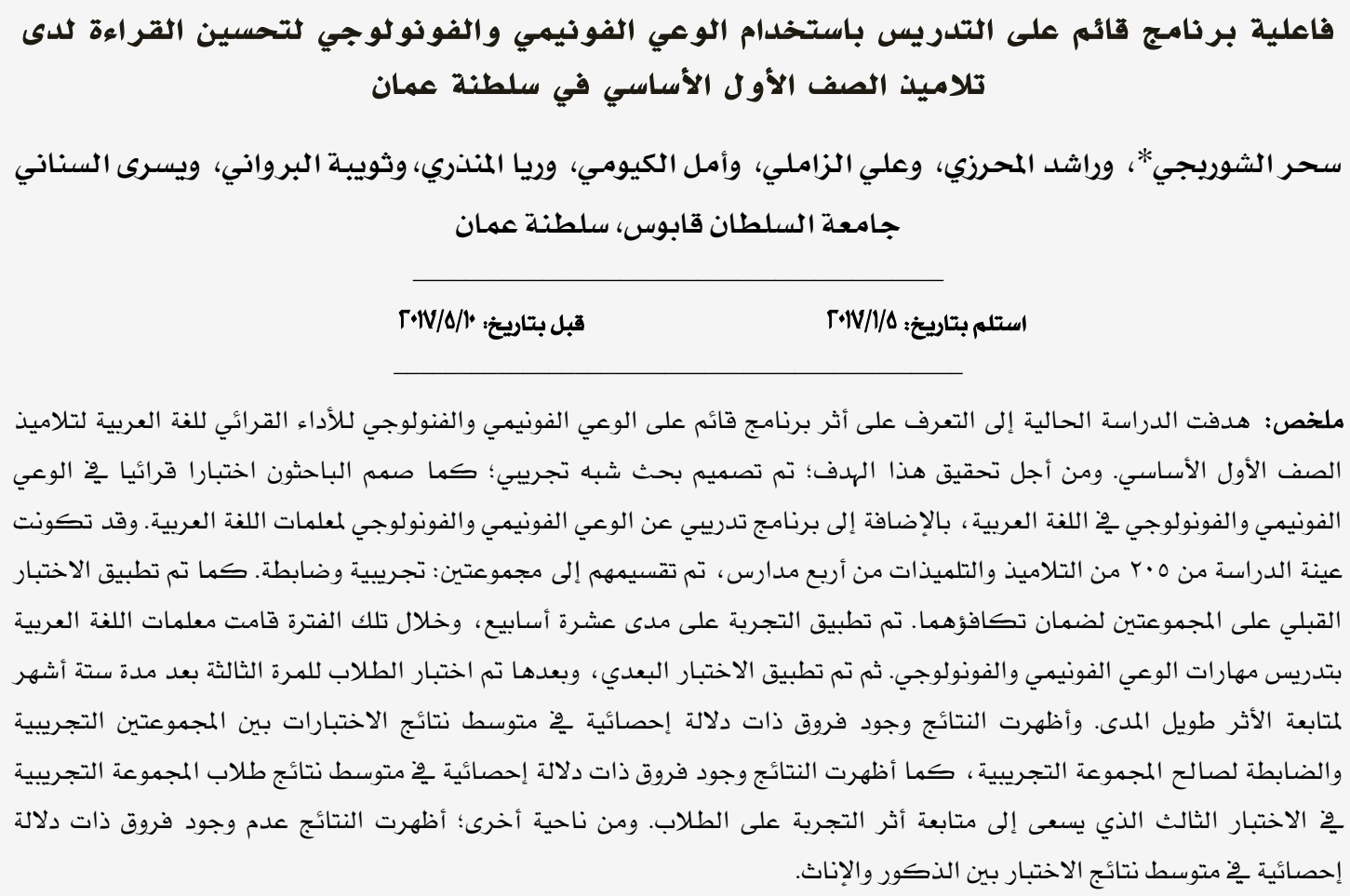

\title{
The Effectiveness of Phonemic and Phonological Awareness Program To Improve Reading Performance of First Grade Basic Education Students in Oman
}

Sahar El Shorbagi* Rashid Al Mehrizi, Ali Al Zamli, Amal Al Kayoumi, Raya Al Munthiri, Thuwyba Al Barwani, Yusra Al Sinani

Sultan Qaboos University, Sultanate of Oman

\begin{abstract}
The aim of the study was to investigate the effect of a phonemic and phonological awareness program, on the Arabic reading performance of first grade basic education students in Oman. To achieve this aim, a quasi-experimental research design was adopted. An Arabic phonemic and phonological awareness test was designed together with training program for Arabic teachers. A sample of 205 students was selected from 4 schools and divided into two groups. The experiment was conducted in 10 weeks during which teachers taught using the program. A post-test was administered after the intervention and then the students were tested for the third time after six months to determine the delayed effect. Results showed that there were significant differences in the mean of the test scores between the control and the experimental groups in favor of the experimental group. Similarly, significant differences were indicated in the mean of the test scores among the experimental group between the pre and the post-test. On the other hand, no significant differences were noted between male and female students. Results also showed significant differences in the mean of the test scores among the experimental group in the third testing which was intended to measure the delayed effect.
\end{abstract}

Keywords: Phonemic and phonological awareness, Arabic reading test, program based on phonemic skills, students in Oman.

*sahar@squ.edu.om

شكر خاص موجه الى مجلس البحث العلمي بسلطنة عمان على دعمه لهذا البحث برقم (RC/EDU/CUTM/14/01) 
Institute of Child Health and Human Development (NICHD), 2000)

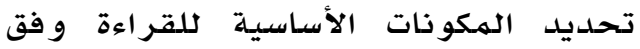
براهين علميلة ثابتة ومعرفة أفضل الطرق التي تسهل عملية تعليهها و تعلهمها وتخفف من تدني المستوى القر ائي للتلاميذ لاحقا.

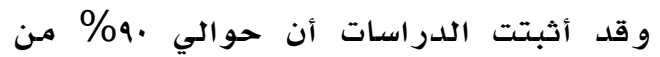
التلاميذ ذوي الصعوبات في القراءة يعانون

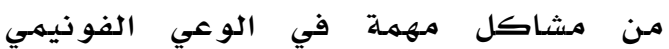
و الفوذولوجي. ومن هنا بلدأ الاهتمام بهذئ

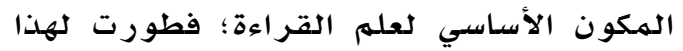
الغرض اختبارات لقياسـه منذ بـاية رياض

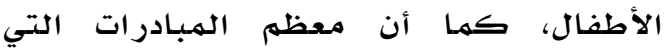
أطلقتها وزارات و مراكز بحوث جامعية ودور نشر تشهل عنصر الوعي الفونيهي و الفو ذو لوجي لتجنب صعو بات كثيرة يصعب حلها لاحقا.

و تواجه سلطنة عمان في ذلك، شأنها شأن دول كثيرة أخرى، تحديات جلدية في تحسين تعليم القراءة وتعلمها خصدوصا احسا في إطار دولي يتميز بالمقارنات التربوية سواء

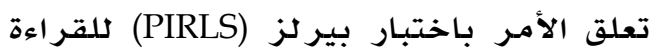
في الصف الر ابـع؛ حيث جاءت نتيجة السلطنة

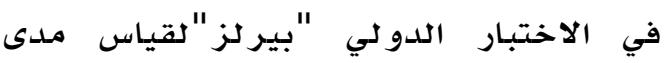

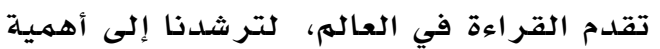
تشجيع مثل هذه الأبحاث؛ نظرا لتسجيلها

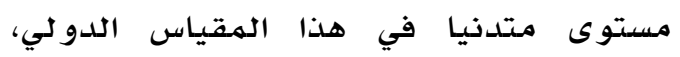

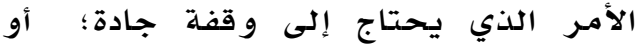

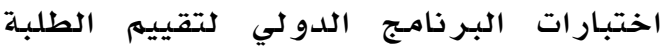

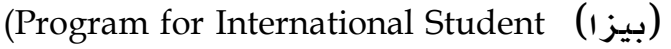
Assessment (PISA) العالمية للدرياضيات و العلوم (تيميس) للصفوف الكلاحقة التي تمثل إتقان (TIMSS) القراءة أحد العوامل الخفية الهؤثرة في جودة نتائجها، وإن له يكن هذا جليا لغير إهدري

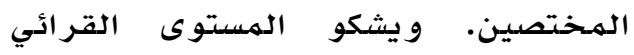
للتلاميذ في سلطنة عمان من نقائص عديدة أظهرتها الملاحظات الميدانية اليومية
تمثل القراءة مهارة أساسية ليس فقط للنجاح الأكاديهي بل أيضا للنهو الههني، و مواكبة التطور المعرفي، و الهسـاهمـة في بلهي بناء مجتهـع المعرفة، وتسهيل حياة الإنسان

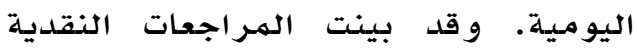
للبحث العلهي بصورة قاطعة أن الوعي

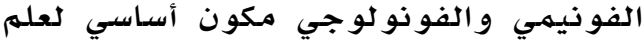

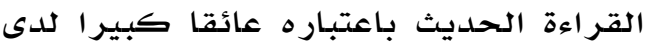

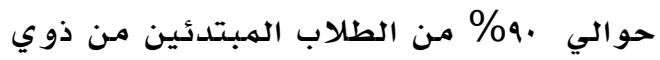

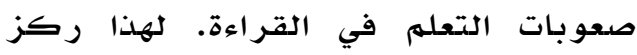
الغرب اهتمهامها على إدراج الوعي الفونيمي

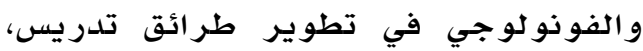
وبناء المناهج، و وتقنين اختبارات السن المبكرة. و بصفة عامـة؛ يتسسم تدريس اللغلة العربية في الصف الأول في معظم الهـ الدول

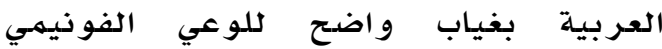

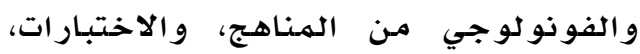

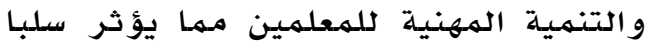
على مهارة القراءة وعلى التحصيل الدراسي لهيل ككل.

ويتميز العصر الحلديث بحتمية تطوير

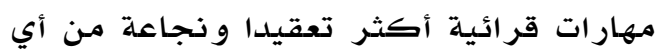
وقت مضى كههارات أساسية للنجاح في مجالات حياتيلة عديدة، مثل مواكبة الانفجار

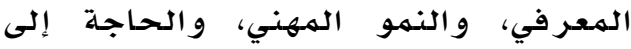
التو اصل بو اسطة التقنيات الحديثة، و التر فيه، و إنجاز مهام مهنية. و ويمثل تعلم القراءة

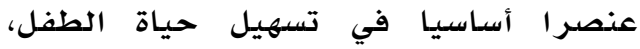
باعتبار أن تعقدها يتطلب توظيف مهارات

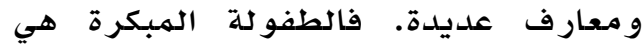
المـرحلة الأكثر حساسية في تعليم القراءة (Justice, Bowles, \& Skibbe, بشكل فعال

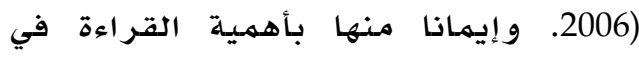
المحافظة على التفوق الاقتصادي وتهادي العديد من الهشاكل الصدحية والاجتمهاعية؛ أجرت الولايات المتحددة الأمـريكية مـر اجعتين

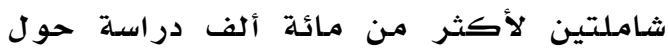

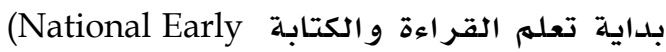
Literacy Panel (NELP), 2008 a,b ; National 
تتجمهع هذه الأصوات لتعطى مقاطع، ثم كلمات، ثم جمل، والأصوات هي المـادة الخام

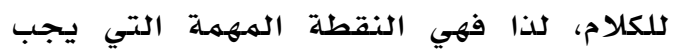

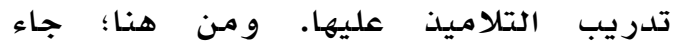
التفسير الأكثر شيوعا للعسر القرائي، الذي

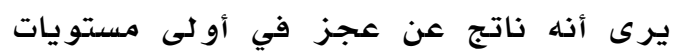
اللغة وهو المستوى الفونيمي و الفونو لوجي؛ بسبب صعوبة في تحديد أصدوات الكلمات

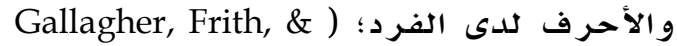

.(Snowling, 2000

و يعد الوعي الفونيمي و الفونولوجي أو علهم

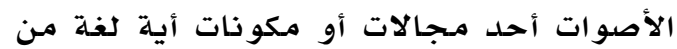

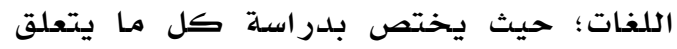

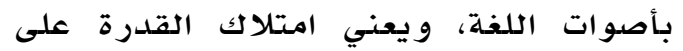

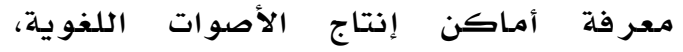
وكيفية أو آلية إخراج هذه الأصدوات، و الكيفية التي تتشكل فيها هذه الأصوات مـع إحل بعضها لتكوين الكلمات والألفاظ مـع القدرة

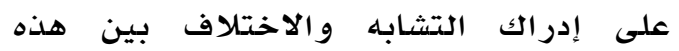
الأصوات، سواء جاءت هذه الأصوات مفردة أو

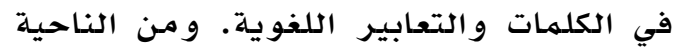
العلمية ؛ فإن الوعي الفونولوجي يعني امتلاكك الطفل لقدرات تتجاوز اللغة أي إلى ما ورواء

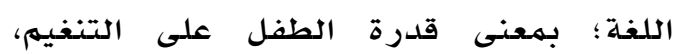

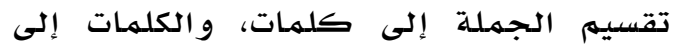

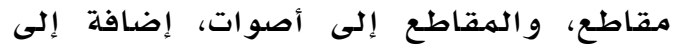

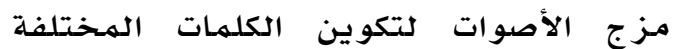

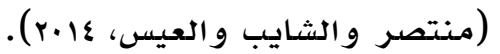

كما يعرف الوعي الفونولوجي بأنه القدرة

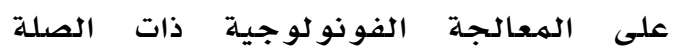
القوية لتعلهم القراءة و الكتابة و تشتهمل على لهولى لهوله

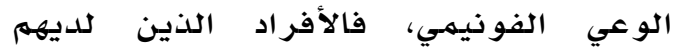

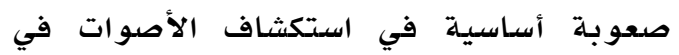
الكلمات و استخدامها سوف يعانون صعوبة Anthony, \& Francis, ) في تعلهم القراءة 2005). و يلعب الوعي الفونيمي و الفونو لوجي راءه راهي الدور الأساسي في اكتساب اللغة، كها أن الن

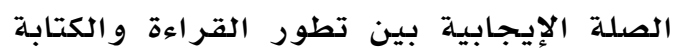

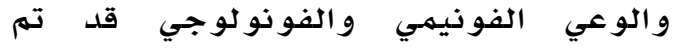

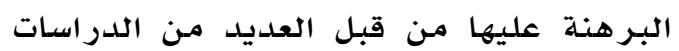

للتربويين بمـختلف فئاتهم (معلمين،

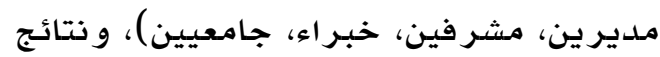

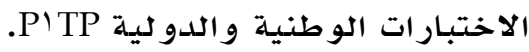

وتعتبر القراءة من أهم الههارات التي

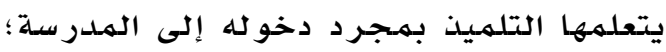

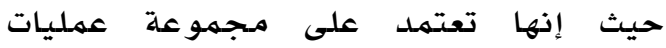

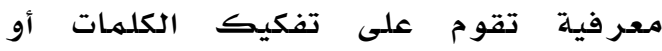

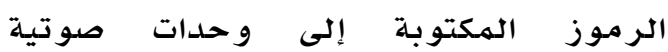
للوصدول إلى مـرحلة الفهم والإدر الك المعر في

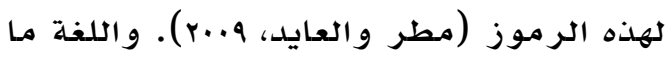
هي إلا أصوات ورموز منطوقة و ومكتوبة

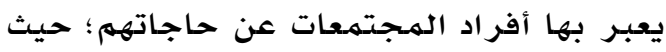

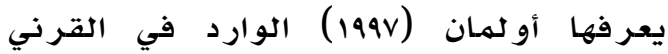

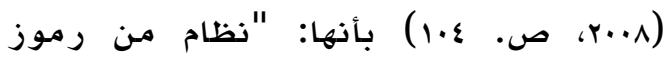

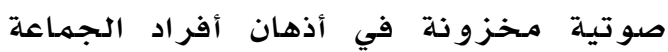

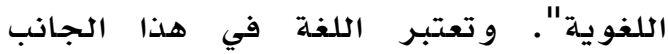

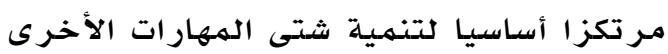

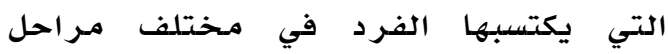

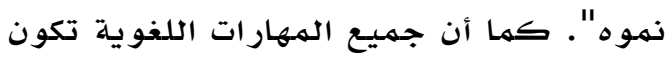

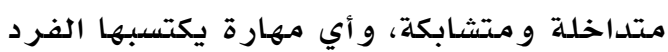
تساعده على اكتساب المهارات الأخرى.

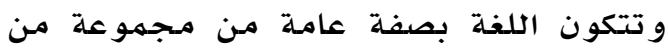

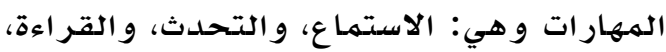

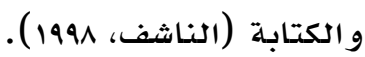

وتهدف عملية تعليهم القراءة إلى إكساب

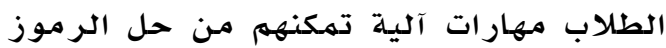

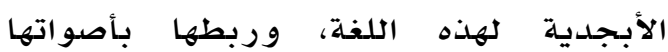
المعينـة لكي تشكل الكلمات و العبار ات و الجمل ولهل

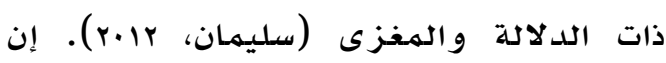
لتعليهم القراءة أهميتها البالغة لدى لدى تلاميذ الهيذ

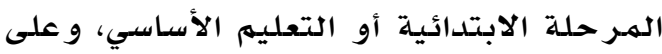

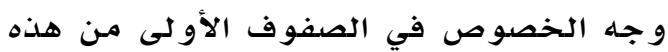
الهـر حلة (رجب، V...V).

و يؤكد بير نشتاين و تايغر مان ( Bernstein,

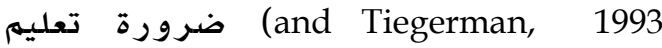
أصوات حرو ف اللغة، باعتبار ها المهيزة لهذيذه اللغة، فلكل لغلة أصدوات محددة روموزها، 
العلاقة بين الوعي الفونيمي والفونولوجي

والقراءة

يشير ليرنر (Lerner, 2000) إلى أن معظم

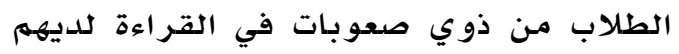
مشاكل أخرى في باقي المواد الدراسية التي

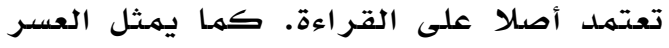

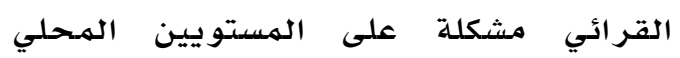
و العالمي وبنسب لا يستهان بها، مما يشكل عبئا و فاقدا حقيقيا بين تلاميذ تؤهلهم قدراتهم العقلية على النجاح و التفوق أحيانا،

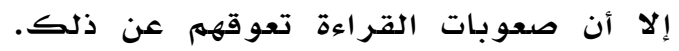

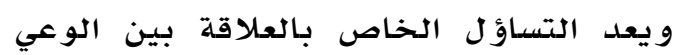

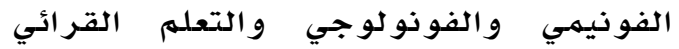

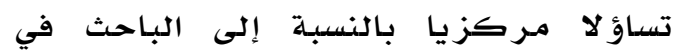

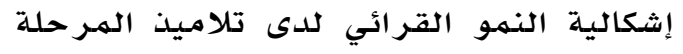

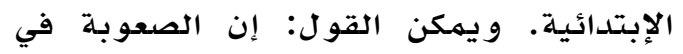

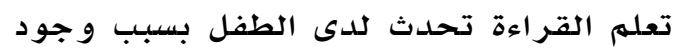

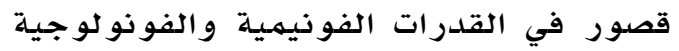
لدى الطفل (سليمان، با.r). و وقد التد بينت الدراسات العلمية في مجال النمو النمال اللغوي

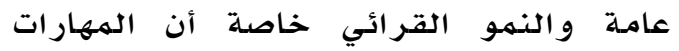

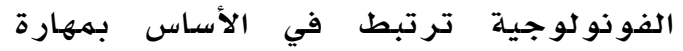

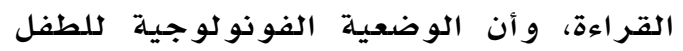
تتحكم إلى حد كبير في وضعيته القرائية

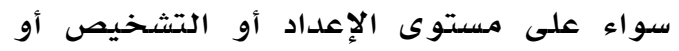

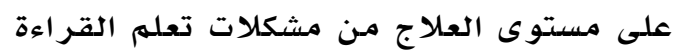

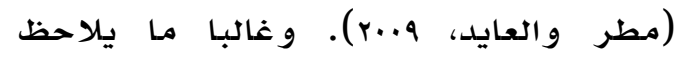

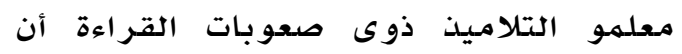
المشكلة ناتجة عن عدم القدرة على التمثيل

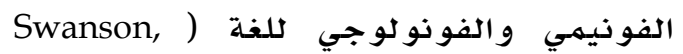
2000)؛ حيث تظهر المشكلة لديهم عندما لوني يتقدمون لاختبارات التي تتطلب منهم معالجة الوحدات الأكبر للكلمات المنطوقة التئة

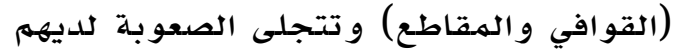

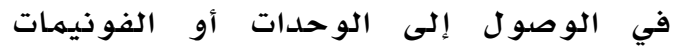
الأصغر (منتصر، و الشايب، و العيس، عالـr). ولقد كشفت نتائج العديد من الدراسات عن العن الدئ القصور لدى المصابين بالعسر القرائي فيما

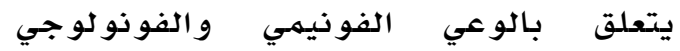
بالوحدات الصرفية، ومن هذه الدرواسات على ونى

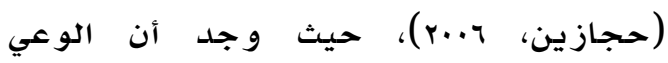

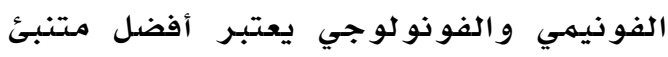

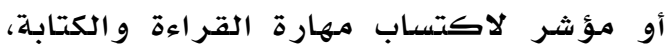

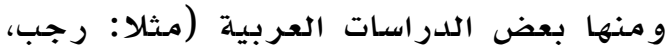

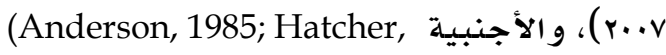
\& Hulme, 1999; Hoien, Lundberg, Stanovich, \& Bjaalid, 1995; Lonigan, Burgess, \& Anthony, 2000; Macmillan, .2002)

و تكمن أهمية الوعي الفونيمي والفونو لجي في أن تعلم القراءة يتطلب معرفة النة صريحة

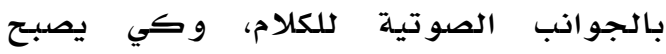

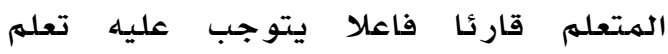

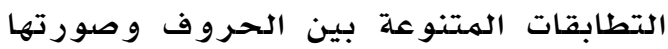

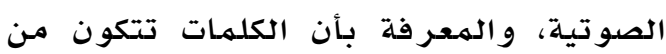
صور صوتية غير متلاصقة تعد أساسية لبناء قواعد الترابط بين الصور الصوتية ورسمها،

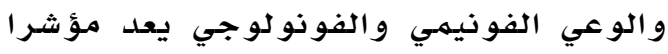
بصورة أكبر من معامل الذكاء، و المفردات

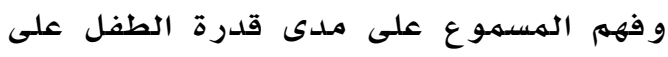

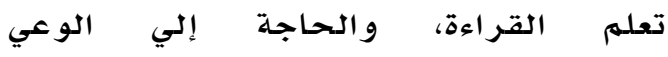
الفونولوجي والفونيمي لا تتمثل في أهميته

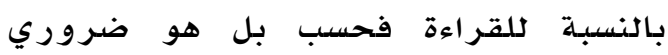

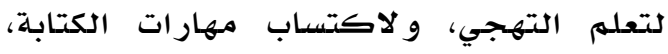

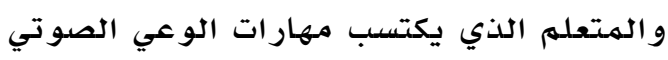
لن يكون بإمكانه أن يتعلم القراءة- فقط-

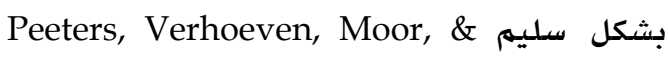
(Balkom, 2009)، بل سيتمكن من تهجئة الكلمات بصورة صحيحة دون استظهارها

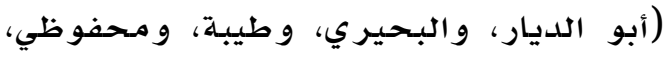

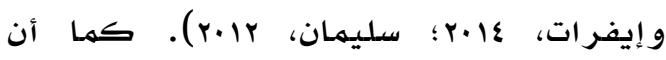
القدرة على معالجة أصوات اللغة ومهارات

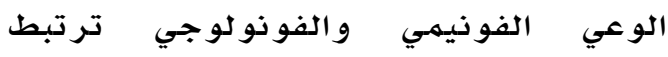
بدرجة عالية بالقدرة على القراءة و التهجئة

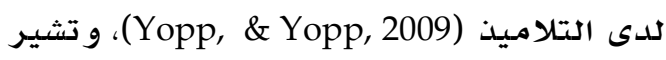

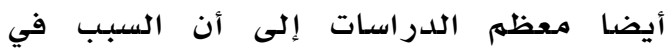

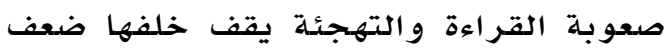

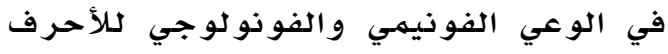
و المقاطع (أبو الديار و آخرون، عالـr). 
الدراسـة أن تعليهم الوعي الفونيمي يظهر

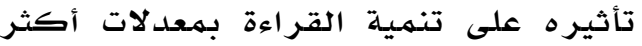

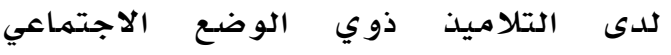
و الاقتصادي الهنخفض.

و أوضحت دراسـة إلبرو و بيترسون ( Elbro, (and Petersen, 2004 التأثيرات الإيجابية الطويلة المدى للتدريب

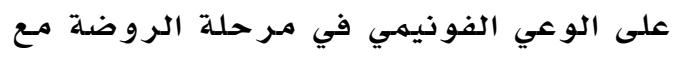

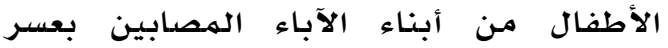

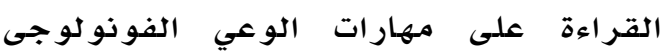

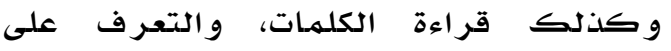
الكلمات غير الصحيحة، و والفهم القرائي.

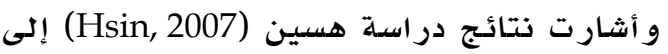
أن تعليم الوعي الفونولوجي كان فعالا لتحسين طلاقة تجزئة الفونيمات لدى جميع لونيع

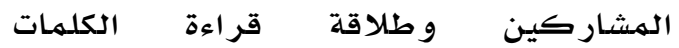
المفهومهة، ولكنه أخفق مـع طلاقة الكلمات

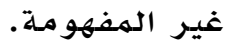

ويتضح من الدراسات السـابقة أن ممارسة

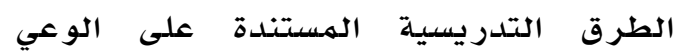
الفونيمي و الفونولوجي لها تأثير مباشر على

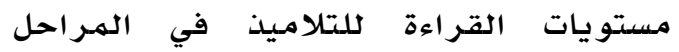

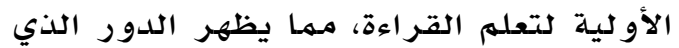
يمكن أن يؤديه الوعي بهاتين الههارتين على الى الهـ تحسن القراءة عند الأطفال.

\section{مشكلة البحث}

لقد تبين من مـراجعة الأدب النفسي و التربوي العربي افتقاره لدراسـات حديثة حول الوعي الفونيمي والفونوني لوجي و وغياب اختبارات تواكب أهم التطورات في مسجال

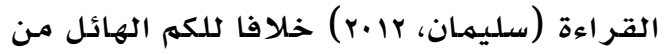
الدراسـات والاختبـارات في البيئات الغربية

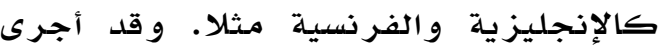
فريق البحث تحليلا لمضمون وثيقة منهج اللغة العربية وكتاب الطالب ودليل المعلم

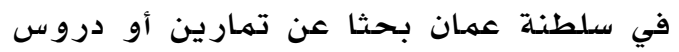
تحتوي على تعليهم مهارات الوعي الفونيمي

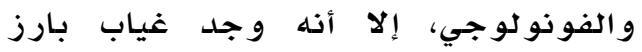

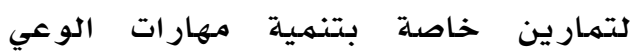

سبيل الهثال، دراسـة منتصر و آخرون (عا.ب)

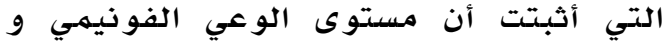

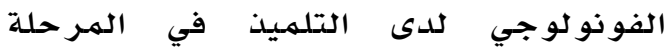
المبكرة، يعتبر مؤشرا دالا على مستوى نموه

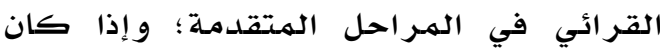
هناك ضعف في مستوى الوعي الفونيمي

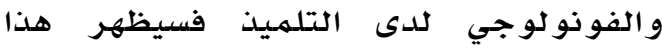
كمشكلة أثناء عملية تعلمه القراءة، لذا فإنان

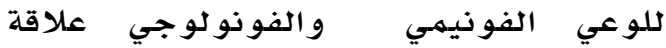
ارتباطية طردية، فكلما نقص مستوى الوعي الفونيهي و الفونولوجي زادت مشاكل تعلهم القراءة لدى التتلاميذ. و وأشار باربوسيا

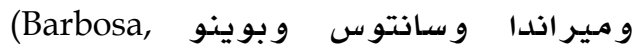
أيضاMiranda, Santos, and Bueno, 2009)

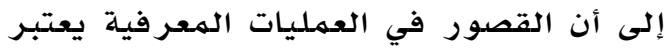

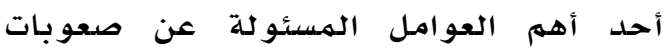

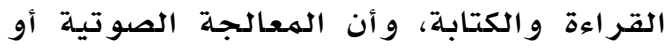

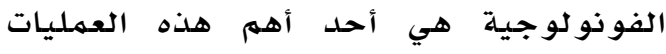

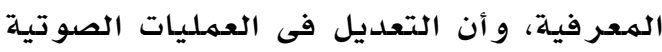

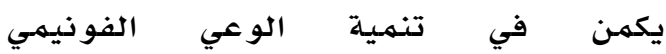
و الفو نو لو جي.

و قد أوضح مطر والعايد (q..... أن العلاقة بين الوعي الفونيمي و والفونو لوجي و وتعلهم القراءة تتحدد مـن خلال ثلاثثة أبعاد هي: بعدي

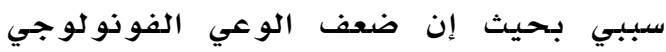
يؤدي إلى العسر القرائي، وبعد تنبؤي بحيث إني إن مستوى الوعي الفونول لوجي للدى الطفل في الهرحلة المبكرة، مؤشر دال على مستوى إنى

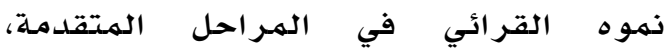
وكذلك بعد علاجي بحيث إن دعم القدرات

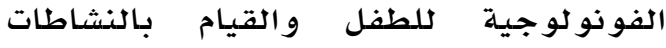

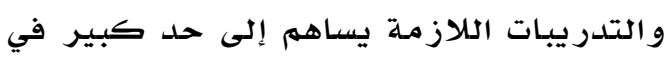
معالجة العسر القرائي؛ مـن هنا تكمن أهمية

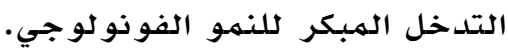

كما أجرى إهري وننيس وويلوس وشوستر

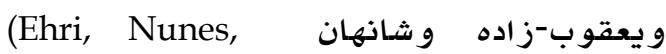
Willows, Schuster, Yaghoub-Zadeh, and Shanahan, 2001) الوعي الفونيهي له تأثير إيجابي على تنهية

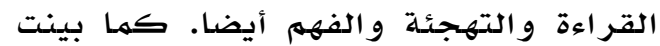




\section{فروض الدراسة}

تستند الدراسة الحالية إلى فحص صحة

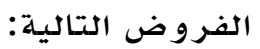

الفرض الأول: توجد فروق دالة إحصائيا

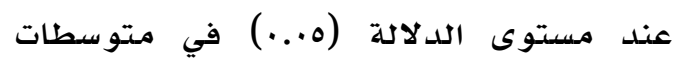

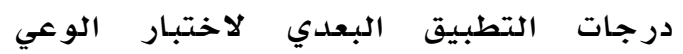
الفونيمي والفونولوجي لطلاب الصف الأول الوليعات الوني

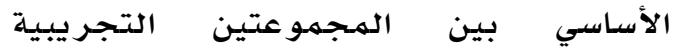
و و الضابطة.

الفرض الثاني: توجد فروق دالة إحصائيا

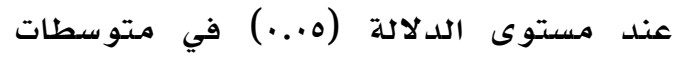

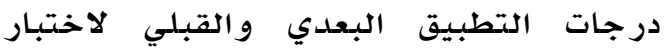
الوعي الفونيمي والفونولوجي لطلاب الصف الأول الأساسي للمجموعة الونيهي والتجرونيبية فقطي. الفرض الثالث: يوجد أثر دال إحصائيا عند

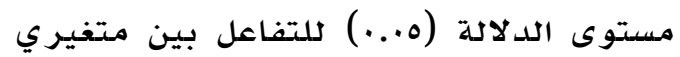

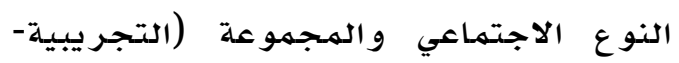
الضابطة) على درجات الطلاب في الاختبار

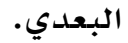

الفرض الرابع: توجد فروق دالة إحصائيا

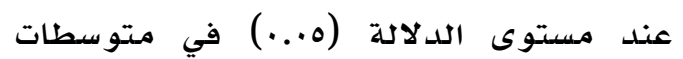

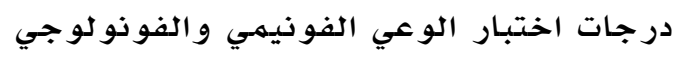
لطلاب المجموعة التجريبية بين التطبيقات التوات الفوني

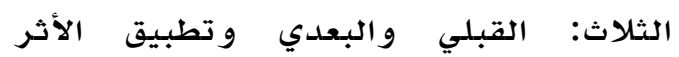
التتبعي للاختبار الثناري

أهمية الدراسة

إن هذا البحث يكتسي أهميته باعتبار القراءة

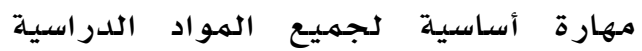
و تطوير مهار اتها في اللغة الأم يؤثر إيجابيا على التحصيل الدراسي في المواد الدراسية

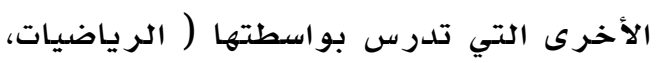

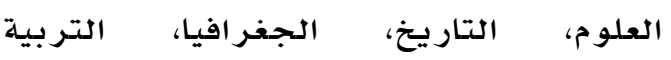

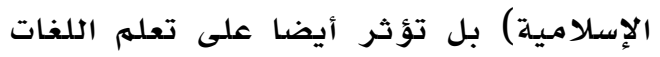

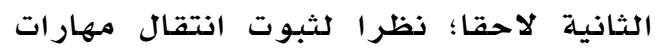
القراءة من اللغة الأم إلى اللغات الأخرى. و تتلخص أهمية الدراسلة في النقاط التالية:
الفونيمي والفونو لوجي لتلاميذ الصف الأول رغم إثبات أهمية هذه المهارات علميا. كمها

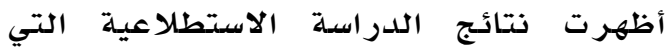

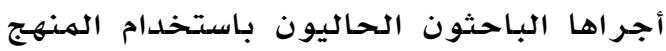

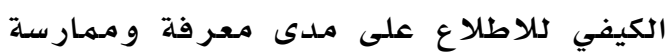

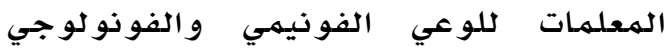

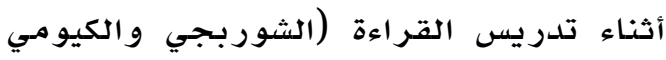

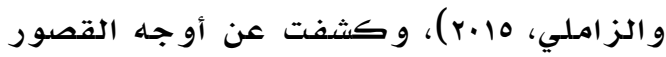

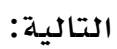
I. عدم استخدام اختبار موحد ومقنن على البيئة العمانية من جانب الوار الوزارة

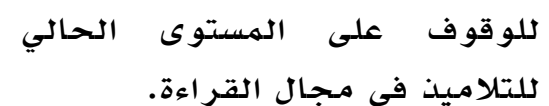
r. عدم وجود برامج تدريبية علمية تساعد في تعليه القراءة ابتداء من تلدرية

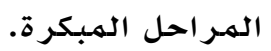

r. الافتقار إلى الأبحاث التطبيقية والتجريبية الوطنية التي تساعد في الإنداث التئية تحديد الطرق المناسبة لعلاج مشكلات القر اءة. - ماءل

و لتغطية هذه الثغرة أجريت الدراسة الحالية، بحيث تتناول مشكلة البحث السؤال

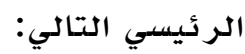

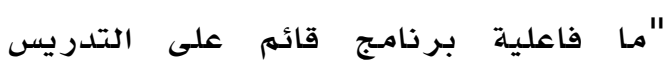

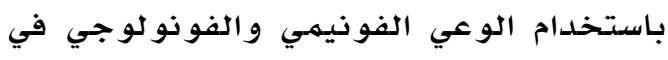
تحسين القراءة لدى تلاميذ الصف الأول الأساسي في سلطنة عمان؟ الحئ أهداف الدراسة تهدف الدراسة الحالية إلى تحقيق الهدف

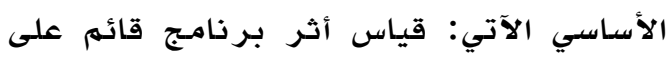

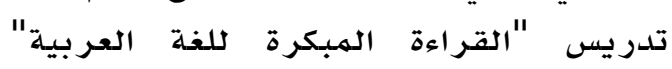

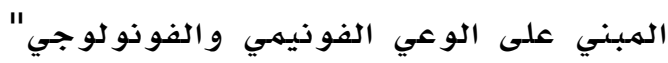
على تحسين الأداء القرائي لدى الفى أفر اد العيندي الفئل

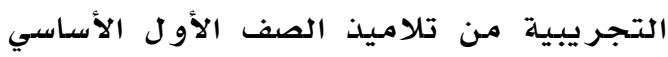
في مدار س سلطنة عمان. 


\section{منهجية الدراسة}

استنادا إلى ما ورد في الأدب النظري

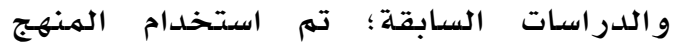

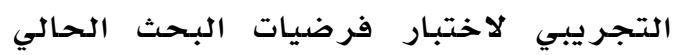

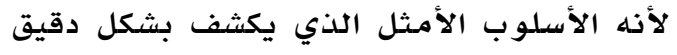

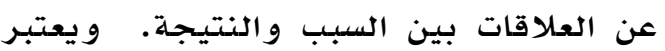
بعض الباحثين هذا المنهج في قمة البحوث العلمية على الرغم من أن البعض الآخر

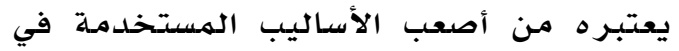

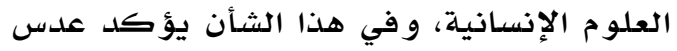
(1999) أن البحث التجر يبي مقارنة بالمناهيج الأخرى عندما يتم تنفيذه بالشكل الدقيق؛ فإنه يعطينا أفضل دليل على صحة العلاقة بين السبب والنتيجة. ويرى كل من جول

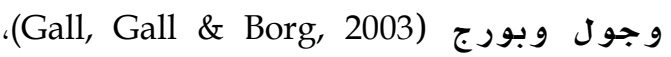

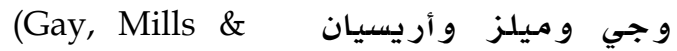
Airesian, 2006) أن التجارب التى تجري في وان المجال التربوي لا تقتصر على عينة البحث التجري

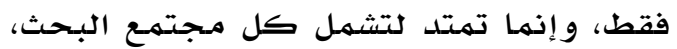

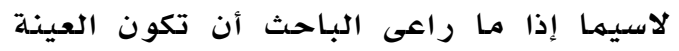

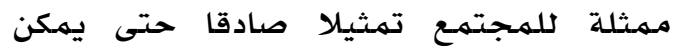
تعميم النتائج على باقى أفراد المجتمعح، وهذا لهاديا

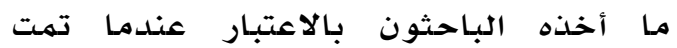

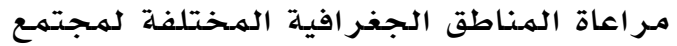

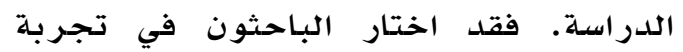
البحث الحالي للصف الأول الاساسي التصميه التئوني

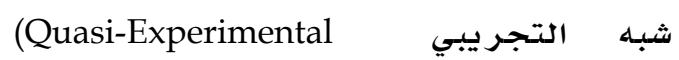
(Design) التصميم الذي يتضمن مجموعتين ضابطة

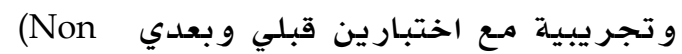
.- Equivalent Control Group Design)

\section{مجتمع الدراسة}

تكون مجتمع البحث من مجموع الطلاب في الإبا

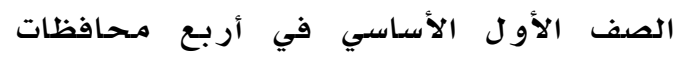

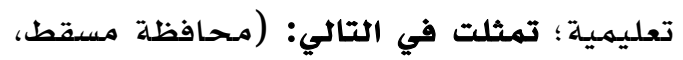

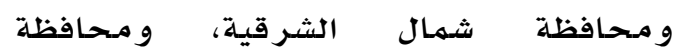

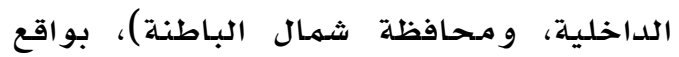

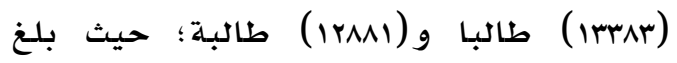

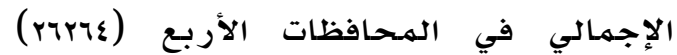

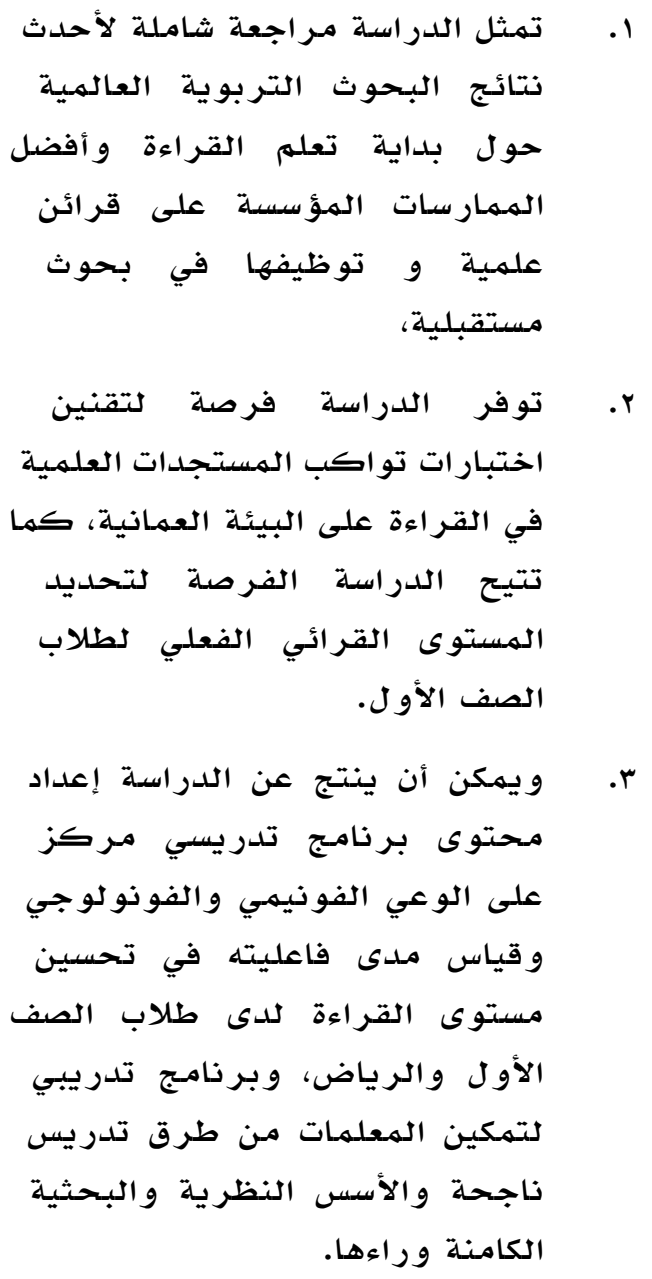


وجلدول ا يمثل توزيع أفراد العينة النهائية ل اللاختبار حسب المتغير ات.

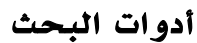

تمثلت أدوات البحث في اختبار تحصيلي

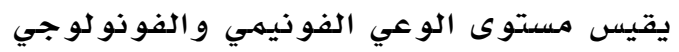
لطلاب الصف الأول الأساسي، إضافة إلى الى الى الى

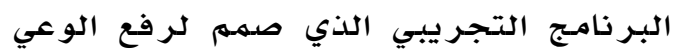
ل - لدى التلاميذ.

اختبار الوعي الفونيمي و والفونولوجي لطلاب الصف الأول الأساسي

وصف الاختبار: يتكون الاختبار من ثماني

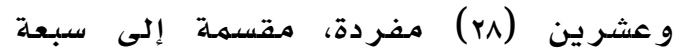

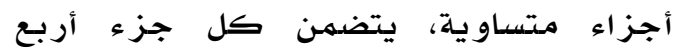
مفردات، حيث تقيس الأجزاء السبعة مجتمعة أنساء

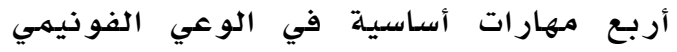
والفوذولوجي لدى طلاب الصف الأول الصاسل الأساسي، وهو اختبار فردي ومحوسب دون

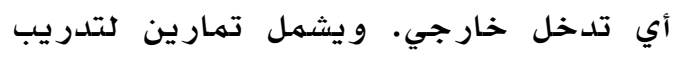

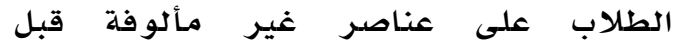
اجتيازها في الاختبار لتفادي إفساد نتائج

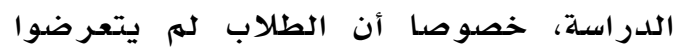

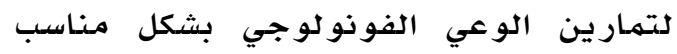
مثل ما يحدث في تدريس لغات أم أخرى.

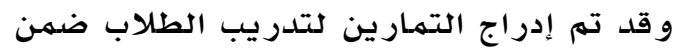

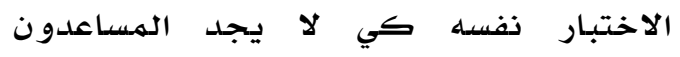
صعوبة في المرور من ملفات التدريب إلى لإنى
طالبا وطالبة وذلك حسب الكتاب السنوي

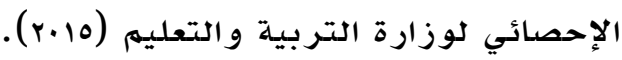

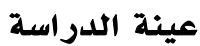

طبق البحث الحالي في أربع محافظات

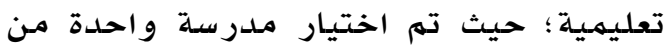

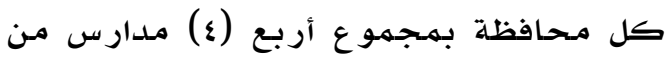
الحلقة الأولى تضم الصفوف (1-ع)، وتم التهم

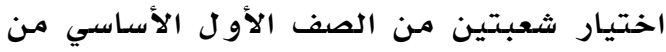

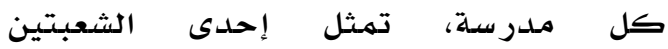

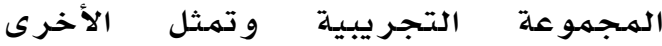
المجموعة الضابطة بشكل عشوائي. بلغ التخدئ

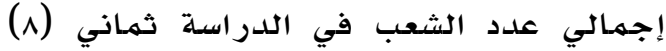

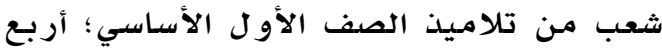

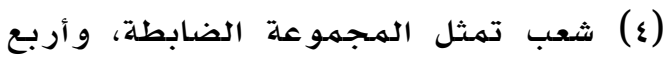

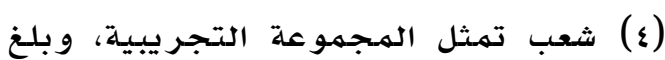

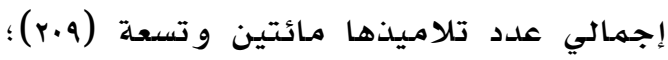

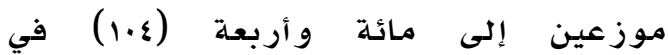

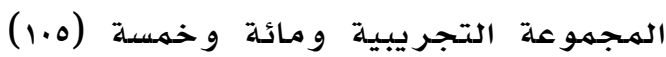
في المجموعة الضابطة، وذلك في التطبيق القبلي كلاختبار. أما التطبيق البعدي ونطالهرا

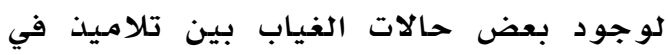

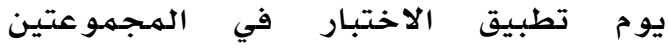

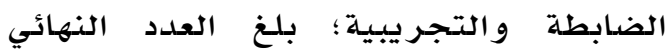

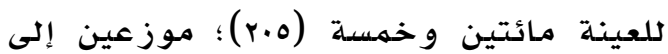

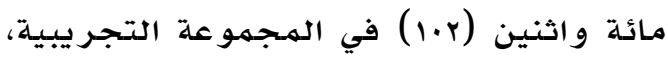
ومائة و ثلاثة (r.1) في المجموعة الضابطة.

توزيع أفراد العينة حسب متغيرات المجموعة والنوع والمحافظة

\begin{tabular}{|c|c|c|c|c|c|c|c|c|c|c|c|}
\hline \multirow[b]{3}{*}{ النسبة } & \multirow{3}{*}{ العدد } & & & & & & & \multicolumn{2}{|c|}{ المحافظات } & \multirow{3}{*}{ النوع } & \multirow{3}{*}{ المجموعة } \\
\hline & & \multicolumn{2}{|c|}{ شمال الثرقية } & \multicolumn{2}{|c|}{ الداخلية } & \multicolumn{2}{|c|}{ شمال الباطنة } & \multicolumn{2}{|r|}{ مسقط } & & \\
\hline & & النسبة & العدد & النسبة & العدد & النسبة & العدد & النسبة & العدد & & \\
\hline$\% 01 . \varepsilon$ & or & $\%$ \%.v & 1. & $\% 17.0$ & IV & $\% \backslash$ Y. & ir & $\% \backslash r .7$ & 14 & ذكور & الضابطة \\
\hline$\% \leqslant \wedge .7$ & 0. & $\% \vee . \wedge$ & $\wedge$ & $\% \backslash 1 . \vee$ & IT & $\% \backslash$ Y. & $1 \pi$ & $\% 17.0$ & IV & إناث & \\
\hline$\% 1 \ldots$ & $1 . r$ & $\% \backslash \vee .0$ & 11 & $\%$ \% . & rq & $\%$ ro.r & rT & $\%$ \%..। & $r$. & المجموع & \\
\hline$\% \leq 0.1$ & $\leq 7$ & $\% 9 . \wedge$ & 1. & $\% 1 \cdot . \wedge$ & 11 & $\% 1 \cdot . \wedge$ & 11 & $\%$ IT.V & $1 \varepsilon$ & ذكور & التجريبية \\
\hline$\% 0 \leq .9$ & 07 & $\% \vee . \wedge$ & $\wedge$ & $\% \backslash \vee .7$ & 11 & $\% \backslash \leq . V$ & 10 & $\% \backslash \leq . V$ & 10 & إناث & \\
\hline$\% 1 \ldots$ & $1 . r$ & $\% \backslash \vee .7$ & 11 & $\%$ \%^.乏 & rq & $\%$ \% 0.0 & rq & $\% \curlyvee \wedge . \varepsilon$ & rq & المجموع & \\
\hline$\% 1 \ldots$ & r.o & $\% \backslash \vee .7$ & ז & \%ҮА. & 01 & $\%$ \% & or & \%ห^.V & 09 & & الجملة \\
\hline
\end{tabular}




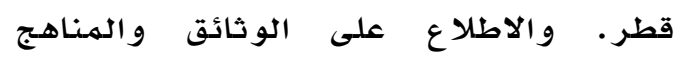

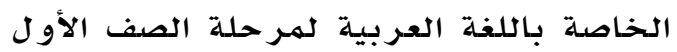

الأساسي.

معايير اختيار الكلمات: تم اختيار الكلمات

المتضمنـة في الاختبار و فقا لكثرة الاستخدام

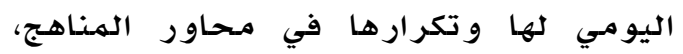

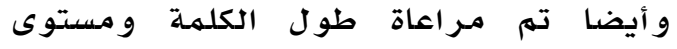

صعو بتها.

ترتيب عناصر الاختبار: تم ترتيب عناصر

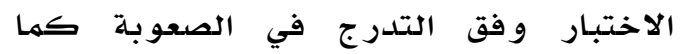

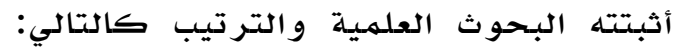

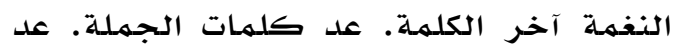

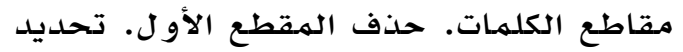

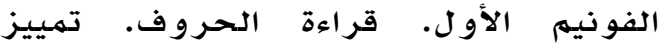

الكلمات الحقيقية من كلمهات غير موجودة.

ووفقا لترتيب عناصر الاختبار المذكورة

آنفا، فقد تم تقسيم الاختبار إلى سبعة (v)

أجزاء مترابطة بحيث تقيس في مهمبلها

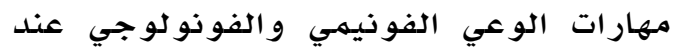

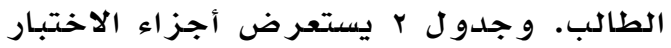

و المهار ات المستهدفة وفل فيه.
الاختبـار مــرات عديـدة. كـذلكـ تــمّم إدراج

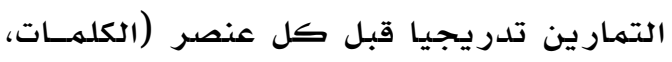

المقاطع، الأصوات)؛ لأن هذا أفضل من فن القيل القيام بها دفعة و احدة في البداية.

خطوات بناء الاختبار: تم بناء الاختبار بعد الاطلاع على عدة وثائق ذات الصلية، وهي:

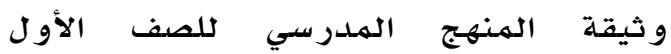

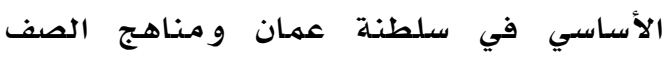

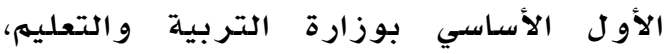
و تمثل إطار التقويم

بالاستعانة بعض الاختبارات الأجنبية مثل

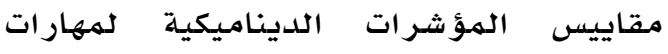

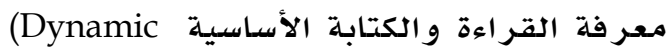
Indicators of Basic Literacy Skills

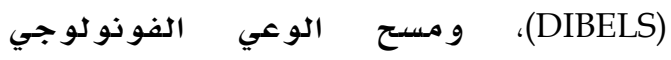

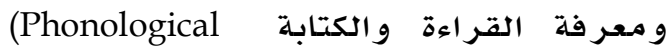
Awareness and Literacy Screenings (PALS) ، وتقييمات فلوريدا لتدريس القراءة

Florida Assessments for Instruction in ( ) (Reading (FAIR)

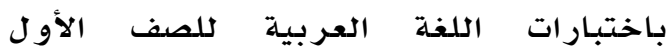
الأساسي في كل من سلطنة عمان ودولة لئ

بنية الاختبار والمهارات المستهدفة فيه

\begin{tabular}{|c|c|}
\hline المهارات المستهدفة المهة & الأسئلة \\
\hline والمعالجة الصوتية الدقيقة آلنمة الكلمة يعتبر من ضمن المهارات التي تدل على قدرة الطفل على التمييز الصوتي & $\varepsilon-1$ \\
\hline تقيس وعي الطفل بالكلمات كمكونات أو وحدات منفصلة داخل الجملة & $\wedge-0$ \\
\hline القدرة على تعرف وجود عدد معين من المقاطع في الكلمات هذه الأسئلة تقيس مهارة المقاطع & $r-9$ \\
\hline بطريقتين: & $17-14$ \\
\hline 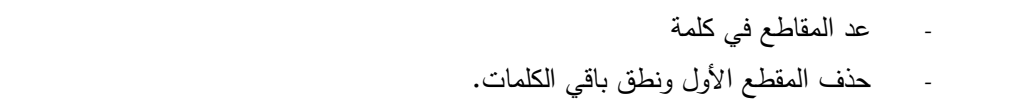 & \\
\hline تقليس الأسئلة قدرة الطفل على تحديد الصوت الأول في الكلمات باعتبار أن تغير الصوت الأول يؤدي & $r \cdot-I V$ \\
\hline الربط بين صوت الحرف والرمز المكتوب. & $r \varepsilon-r$ \\
\hline مهارات القراءة باعتبارها تشمل توظيز الكلمات الحقيقة من كلمات غهار غير موجودة ولكنها مشابهة هي أفضل مؤشر لقياس & $r_{\Lambda}-r_{0}$ \\
\hline والتعرف إلى الكلمة التي تمثل الصورة من كلمات تستخدم حروفا منتابهة مع حروف الكلمة الصحيحة & \\
\hline
\end{tabular}


ذلك تم تصحيح معامل الارتباط بين النصفين بواسطة معادلة سبير مان- بروان. وقد بلغ معامل الارتباط بعد التصديح

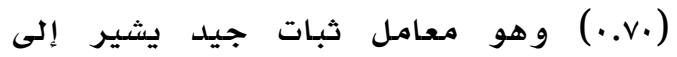
درجة ثبات مقبو لة تلاختبار •

معامل ألفا كروثباخ: تم حساب معامل ألفا كرونباخ نلاختبار ككل من خلال تطبيقه على عينة استطلاعيـة مكونة من (v•) تلميذا

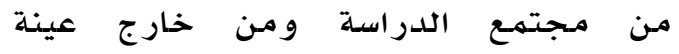
الدراسة ؛ حيث بلـغ معامل ألفا كروذباخ و هو معامل جيد و مقبول و يشير إلى (.VA) درجهة مقبورلة من الثبات مـما يسمهح باستخدام الاختبار لأغر اض الدر اسـة.

\section{تكافوء المجمو عتين (التجريبية والضابطة)}

للتحقق من تكافوء المجموعتين التجريبية

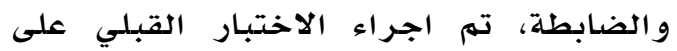

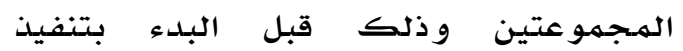

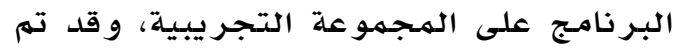

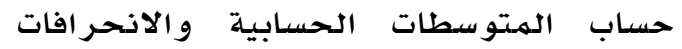

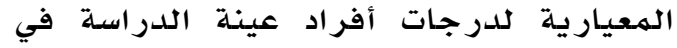

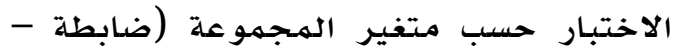

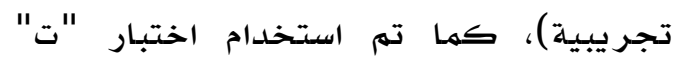

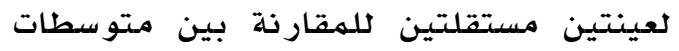

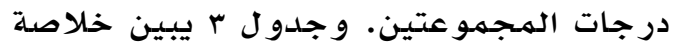

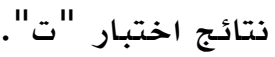

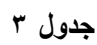

نتائج اختبار "ت" في درجة اختبار الوعي الفونيمي

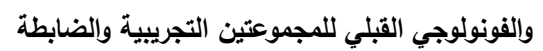

\begin{tabular}{|c|c|c|c|c|}
\hline قيمة "ت" & $\varepsilon$ & r & العدد & المجموعة \\
\hline & E.74 & $1 \xi . V T$ & $1 \cdot \varepsilon$ & تجريبية \\
\hline
\end{tabular}

$(د \dot{\varepsilon}) \cdots 9$ الضابطة

يتبين من جدول r أن قيمة "ت" غير دالة

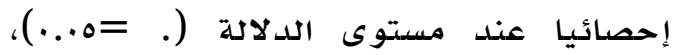
وهذه النتيجة تشير إلى عدم وجود فروق دالة في متوسطات درجات الاختبار القبلي إلي بين طلاب الهجموعة التجريبية وطلاب الهجموعة الضابطة، مها يشير إلى تكافؤ

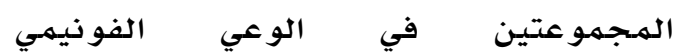
و الفونولوجي قبل البدء بـالتجر بـة.
صدق وثبات الاختبار: تم التحقق من صدق الاختبار بطريقتين:

الصدق الظاهري: حيث عرض الباحثون

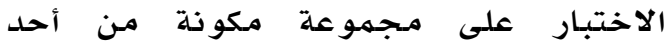

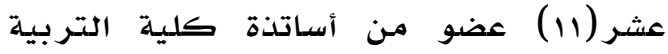
(تخصصي لغة عربية وقياس وتقويه)

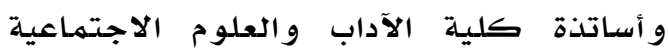

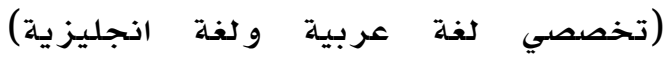

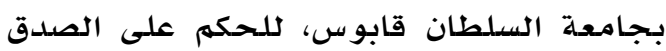
الظاهري للاختبار، حيث طلب منهم إبداء آرائهم و ومقترحاتهم في أسئلة الاختبار

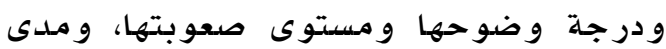

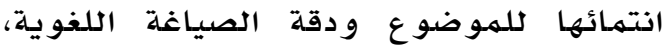

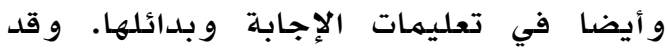
بلغت نسبة اتفاق المحكمين حول الاختبار . (\%^r)

صلدق اتساق الفقرات: تم استخدام معامل ارتباط بيرسون (Pearson's Correlation) لحسـاب معاملات الارتباط بين درجة السؤال

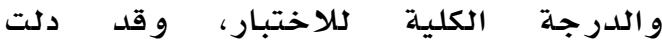

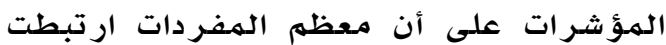

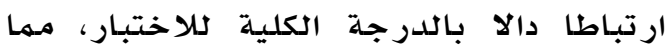
يدل ذلك على صدق بنائه. أما Uبات الاختبار U فقد تم التحقق منـه

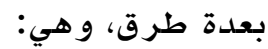
ثبات المصححين: تم تطبيق الاختبار على

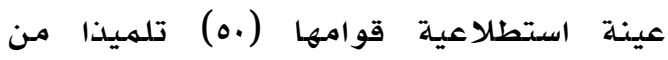

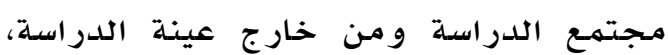
بحيث كان يقوم بعملية التصحيح مصححان

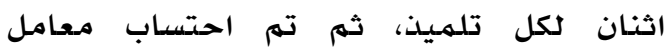
ارتباط بيرسون بين نتائج المصححين، حيث

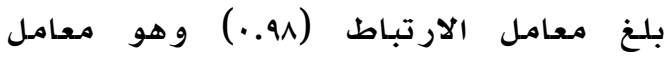
ارتباط مرتفع جدا يشير إلى درجـة ثبات عالية للمصححين.

التجزئة النصفية: حيث تم تقسيه مفردات الاختبار إلى نصفين؛ وضعت الهفردات

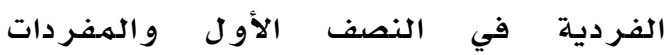
الزوجية في النصف الثاني، ثم تم إيجاد

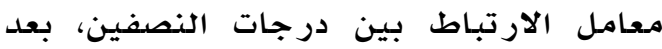


وتهم التركيز على الكلمـات المستخدمة كثيرا في المحيط اليومي للتملاميذ (البيت،

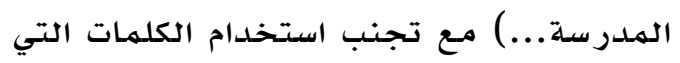
تنتهي للهجات الهحلية. وقد تم اختيار

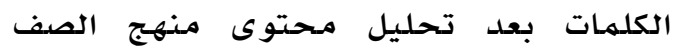

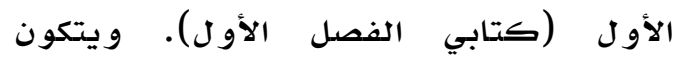

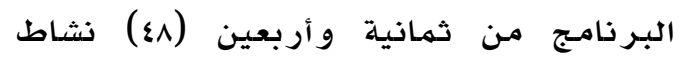
التي توزعت على أربع و وعشرين (

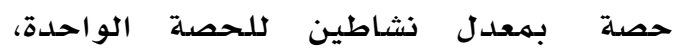

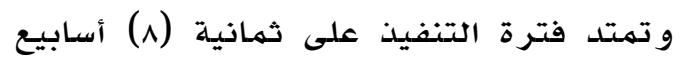
بمعدل ثلاث (r) حصص في الأسبوع، مدة كل حصدة خمس عشرة (10) دقيقة. و قد تم توزيع الأنشطة على امتداد فترة التطبيق؛ أي أنه للم يتم تنفيذ الأنثطة الخاصة بهمهارة

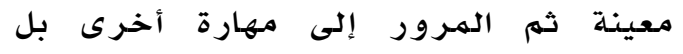

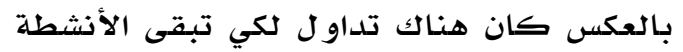

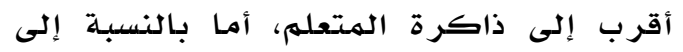

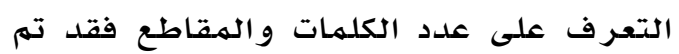
التركيز على العد بواسطة الأصابع لأنه

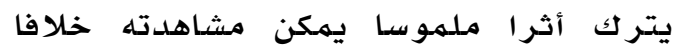
للعد بواسطة التصفيق مثلا. وتجدرر الإثـارة

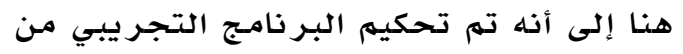

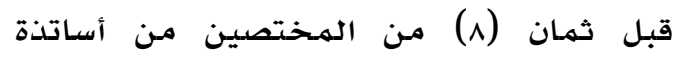
قسهي اللغة العربية واللغة الانجليزية بكلية

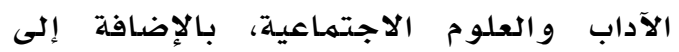
مجموعة من أساتذة قسمر مناهج و وطرق

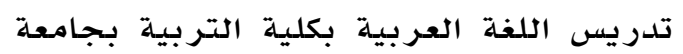

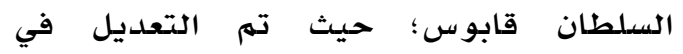
البر نامـج وفق الملاحظات الواردة من قبل لهبل الهحكمين.

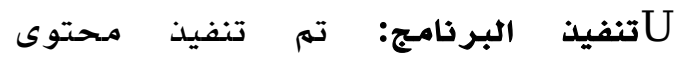

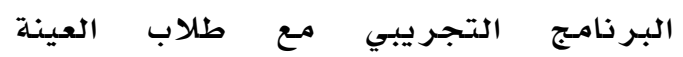

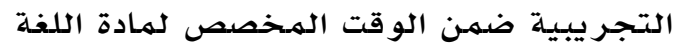

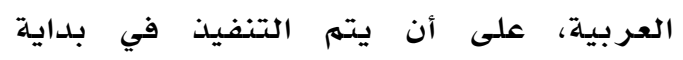

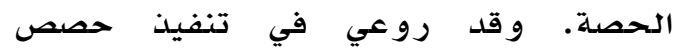

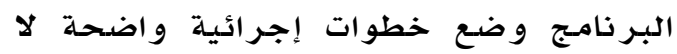

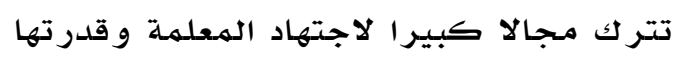
على الابتكار و التفاعل مـع الهادة التي تدرسها

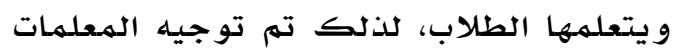

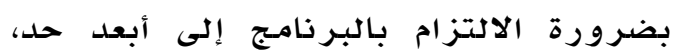

\section{البرنامـج التجريبي}

تصميم البرنامج: تم تصميم كامل المحتوى

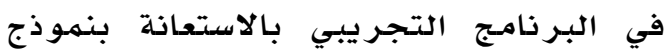

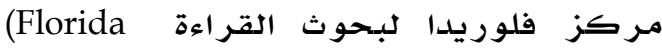
Center for Reading Research; Denton, Ciancio, \& Fletcher, 2006)

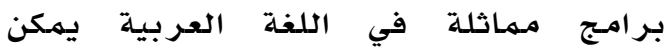

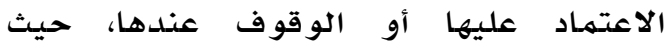
يركز البرنامـج على أربع مهارات أساسية الوهادية

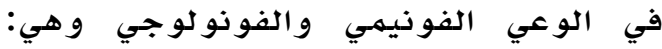

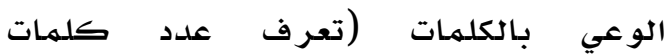

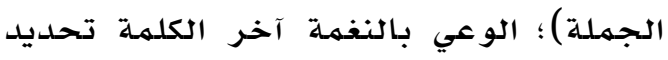

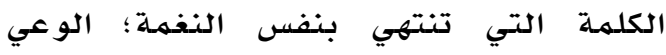

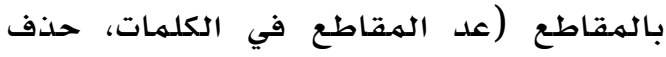

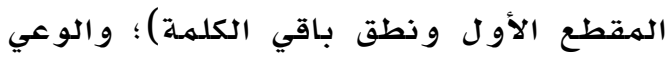

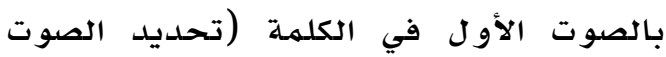
الأول في الكلمـة، تحديد الكلمهة التي تبلدأ بصوت مختلف). و وقد اعتمد في تصدي تصميم طريقة تدريس محتوى البرنامـج على نهوذج

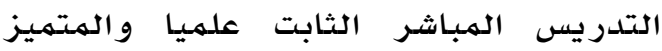

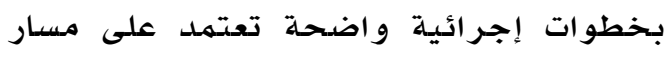
نقل مسؤولية التعلم بصفة تدريجية من المعلمهة إلى الطلاب، ففي بداية الدرس تكون

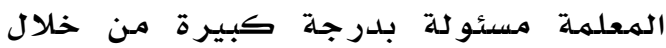

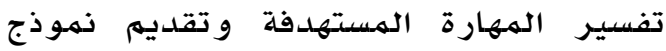
ملموس حول كيفية تنفيذها ثم تنقل المسؤولية تدريجيا إلى الطلاب من من خلابل

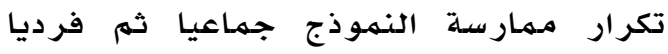
وصو لا إلى نقل أثر التعلهم ثم تطبيق الهـهارة فرديا مـع أمثلة جديدة. وبشكل أدق أدق تتمثل

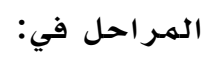

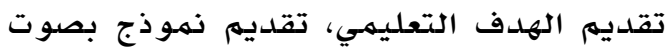
مسموع أمام الطلاب ليشاهلدوا كيفية القيام بالعمل بصورة ملموسة، تمرار تطبيق النمـوذج المعروض من قبل المعلمهة جماعيا، تكرار تطبيق النهوذج المعروض من من قبل

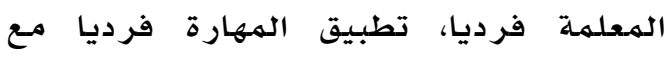
أمثلة جديدة لكي ينقل الطلاب أثر التعلهم إلى وضعيات جديدة. 
0. إعطاء المعلمات فرصا لتطبيق نفس

الههارة كل على حدة.

7. اتتدريب على طرق تدريس معينة

منـاسبـة لعهر الطلاب وتتلاءم مـع

الههارة المطلوبة، بحيث تكون

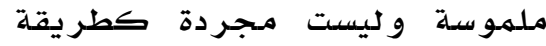

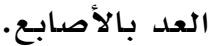

V. تعريف المعلمات بآليات متابعة

تنفيذ البـرنامهج التدريسي من خلال

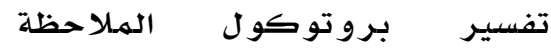

الصفيـة و مكوناتهـ.

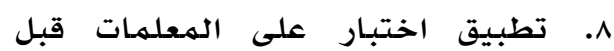

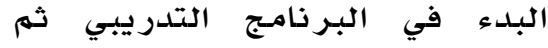

اختبار آخر لقياس أثر التدريب.

تعريف مصطلحات الدراسة

ا. الوعي الفونيمي. ويسمى أيضا بالوعي الفونولوجي للوحدة - و هو الفهم بأن الكلام المنطوق يتشكل مـن مقاطع، وهي بلدورها

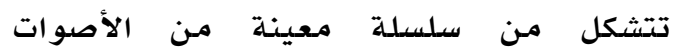

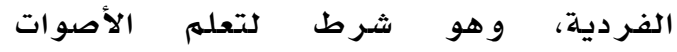
والهقاطع وهو ضروري لتعلم القراءة في اللغة الأبجدية الصوتية مثل اللغة العربية؛ لأن هذه الأصوات الفردية (الفونيهات) تقابل الرموز المكتوبة، وبلدون الوعي الفونيهي والأصدوات لن تتكون لدى الهتعلم الحساسية لتعلم الكلهات وتهجئتها، وسيعتهمد بصورة كلية على حفظ أشكال الكلهات فقط دون فهم بتراكيبها (سليهان، rا.r). و الفونيهم هو أصغر و وحدة صوتية للغة قادرة على تغيير معنى الكلمهة دون أن تحهل

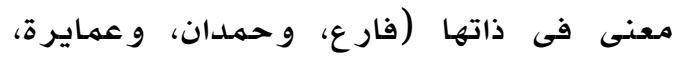

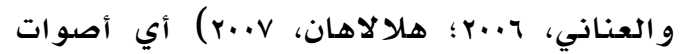

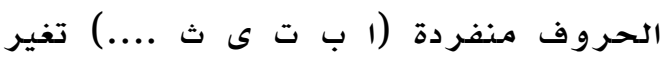
معنى الكلمة (نار - فار - جار - بار - دار -

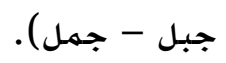

r. الوعي الفونولوجي. يتمثل الوعي الفونولوجي في قدرة الطفل على فهم أن الكلام يهكن تجزئته إلى وحدات صوتية أصغر كالكلمات، و المقاطع، والفونيمات

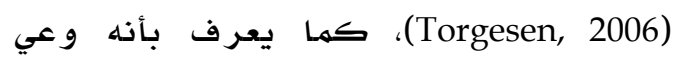

و لكن هذا لا يعني علدم سعي الهـعلمة لتحقيق التعليهم المتمايز بناء على تقييهها لأداء التتلاميذ من خلال إعطاء الفرصة للطلاب الذين تلاحظ لديهم صعوبات في المهارات

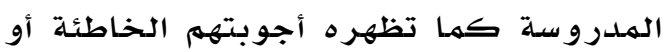
قلة المشاركة وإعادة تنفيذ أنشطة سابقة معهمب.

الجدير بالذكر أن أذشطة الوعي الفونيهي

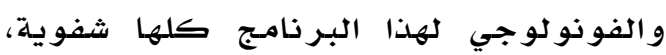
ولذلك فهي لا تشهل كتابة الحروف أو المقاطع أو الكلهات إطلاققا؛ لأنها تركز حصريا على البعد الصوتي للغخة، و مرراعاة للطلاب الذين لديهم نهط تعلم بصري؛ فقد تم استغلال الصور قدر الإمكان في تدريس الوعي بالصوت الأو ل، أمـا بالنسبية إلى طلاب العينة الضابطة؛ فقد تم تلرريسهم حصص منهج اللغة العربية حسب الخطة الدراسية المقرة من وزارة التربية والتعليم دون زيادة أو نقصسان، مـع الأخذ في الحسبـان معادجة كافة مهددات الصدق الداخلي

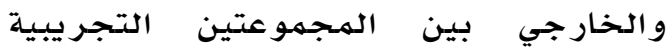
و الضابطة.

البرنامج التدريبي للمعلمات: لقد تم التركيز على بعض النقاط الهامهة أثناء إعداد آلية البـرذامج التدريبي:

ا. تم تدريب الهعلمات الهشاركات بالتجربة لمبدة ثلاثة أيام. r. تم التأكيد على المهارات التي

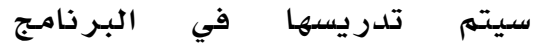

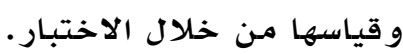
r. إعطاء جر عات " نظرية" من خل خلاسل تعريف الهصطلحسات بدقة. ء. تم توظيف الجـانب العملي مـن خلال: عرض ضيديوهات صامتة ثم بالصوت

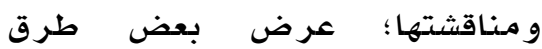

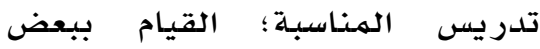
التطبيقات؛ تقلديه عروض؛ مناقشة جمهاعية. 
الباحثين بعملية التطبيق، وقد تزامن

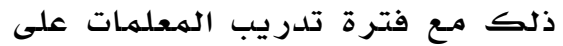
البر نامـج المعد. ه. تم تدريب المعلمهات على البرنامـج

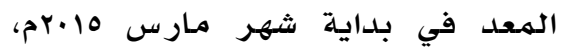
ولمدة r أيام بقاعة تلدريبية مجهزة

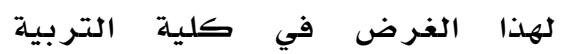
بجامعة السلطان قابوس.

7. امتد تطبيق البرنامـج على عينة البحث (طلاب الصف الأو ل الأساسي) تطيق البرنية

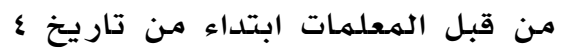
مارس 10 10بم وحتى نهاية شهر أبريل .$r \cdot 10$ V. تم تطبيق الاختبار للمـرة الثانية

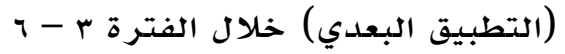

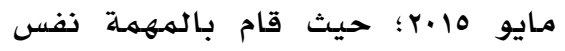
فريق مساعدي الباحثين الذين نفذوا التطبيق القبلي. ^. تم إعادة الاختبار على المجموعة التجريبية بعد ستة أشهر من الانتهاء

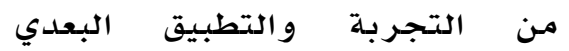

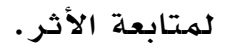

\section{تحليل البيانات}

تم معالجة بيانات الدراسة الحالية في ضوء طبيعتها وأهدافها وأسئلتها حيث أدخلت

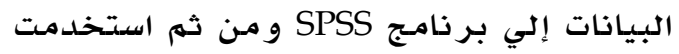
الأسـاليب الإحصائية التالية:

اختبار "ت " لعينتين مستقلتين للمقارنة بين متوسطات درجات المجمهو عتين تم استخدام اختبار "ت" لعينتين متر ابطتين للمقار نة بينهما تم استخدام تحليل التباين الثنائي (Two Way ANOVA)

تهم استخراج المتوسطات الحسابية

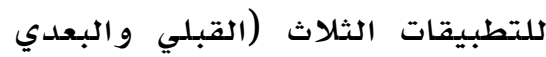
و متابعة الأثر ).
لغوي يمكن الفرد مـن توظيف الهعلومات عن

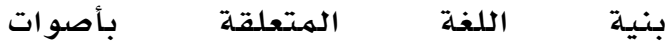
الحلديث (Bennett, 1998). كمما يشير مفهوم

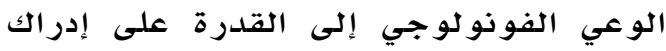

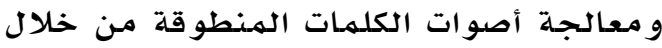

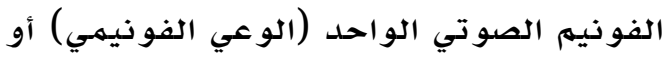

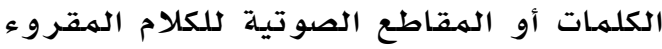
أو الهسهموع (Macmillan, 2002).

أما التعريف الإجرائي للوعي الفونيمي

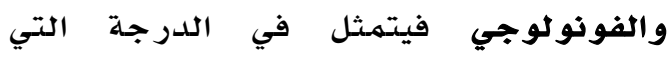

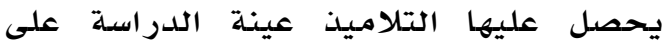

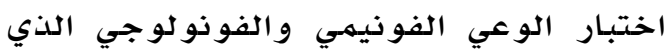

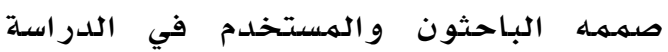

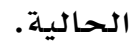

إجر اءات الدراسة

اتبع الباحثون الإجراءات الآتية في تطبيق

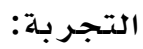

1. بعد الانتهاء من تحكيم الاختبار

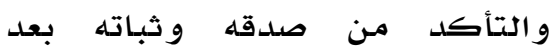
تطبيقه على عينة استطلاعية قوامها مهاه

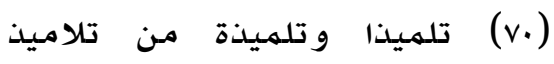

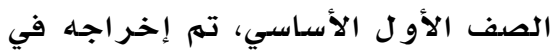
صورته النهائية. Y. تم مخاطبة المكتب الفني للدراسـات والتطوير بوزارة التربية والتعليه عن طريق عمادة كلية التربية

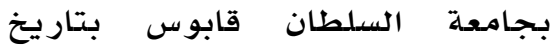

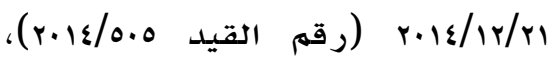
لتسهيل مهمهة الباحثين في التطبيق. r. تمت مخاطبة الملديريات العامـة

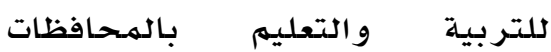
التعليمية المدذكورة حسب عينة

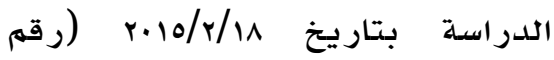

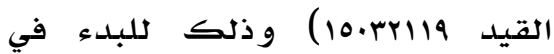
عملية التطبيق الفعلي.

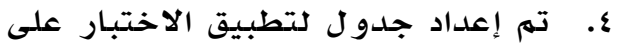

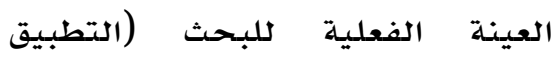
القبلي)؛ حيث قام عدد من مسداعدي الفيلة 
الفرض الثاني: توجد فروق دالة إحصائيا

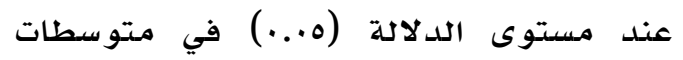
درجات اختبار الوعي الفونيهي والفونو لوجي الوني لطلاب المجموعة التجريبية بين التطبيقين

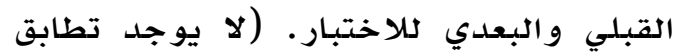

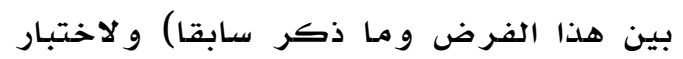
هذا الفرض تم حساب المتوسطات الحسابية

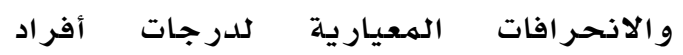

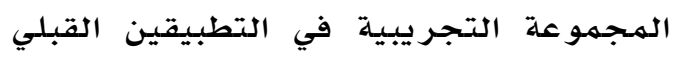

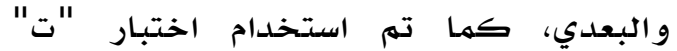
لعينتين متر ابطتين للمقارنة بينهما. وجدول ه يوضح تلك النتائج.

جدول

خلاصة نتائج اختبار "ت" في التطبيقين القبلي والبعدي للمجموعة

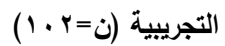

\begin{tabular}{|c|c|c|c|c|c|}
\hline الأثر & الفروق & قيمة "ت" & $\varepsilon$ & ? & التطبيق \\
\hline \multirow{2}{*}{.71} & \multirow{2}{*}{ البعدي } & \multirow{2}{*}{ FIY.Y4 } & $\varepsilon .79$ & $1 \leq .79$ & القبلي \\
\hline & & & \&.Vๆ & 19.99 & البعدي \\
\hline
\end{tabular}

يتضح من جدول ه وجود فرق دال إحصائيا

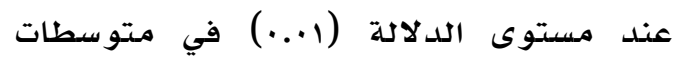

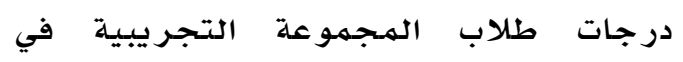
التطبيقين القبلي والبعدي لصالح التطبيق التجات التهوبي البعدي، حيث تؤدي هذه النتيجة إلى قبول الفرض البديل، مما يشير ذلك إلى تلى تأثر الثرد

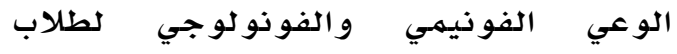

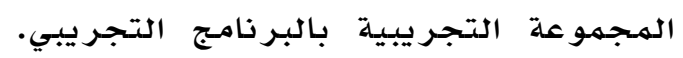

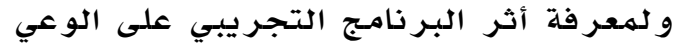

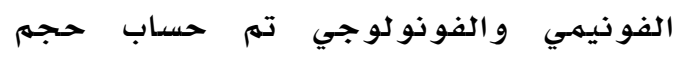
الأثر باستخدام مربع إيتا (Eta Squared)،

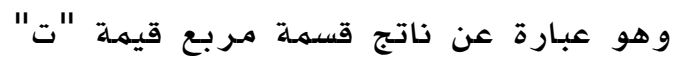

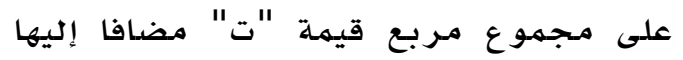
درجة الحرية. وقد بلغت فئت قيمة مربع إيتا في

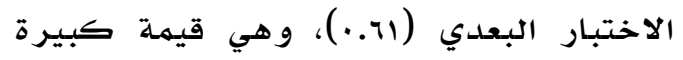

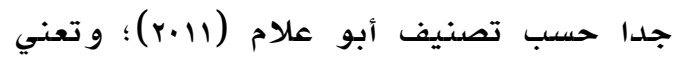

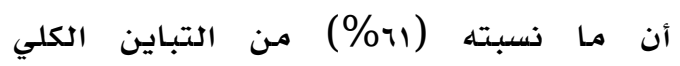
لدرجات الاختبار ، يفسره البر نامج التجريبي. الفرض الثالث: يوجد أثر دال إحصائيا عند

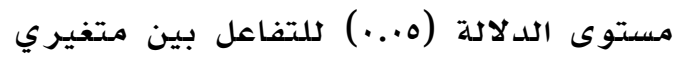

تم استخدام تحليل التباين للقياسات

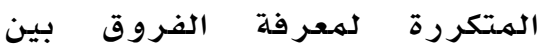

التطبيقات الثلاث

النتائج

يستعرض هذا: الجزء الجية نتائج التحليلات الإحصائية التي أجريت لفحص لفرضئ فرضيات الدر اسة، و هي كما يلي: الاحسية

الفرض الأول: توجد فروق دالة إحصائيا

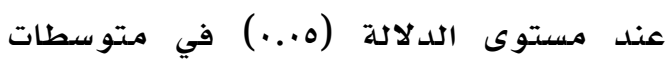

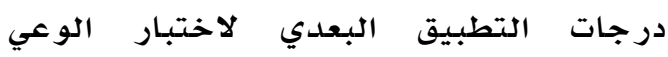
الفونيمي والفونولوجي لتلاميذ الصف الأول

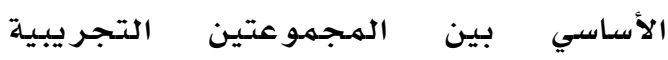

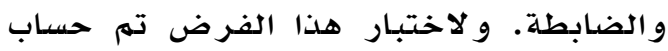

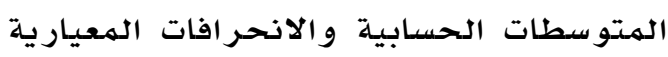

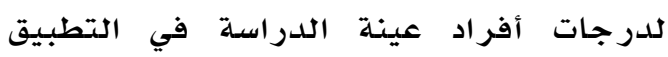

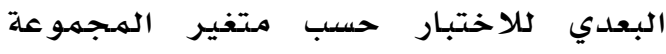

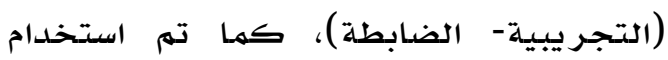

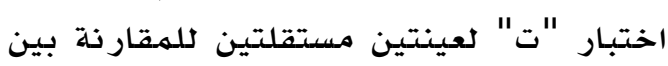

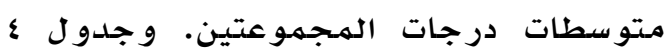
يبين خلاصة نتائج اختبار "ت درجات الهجوعت.

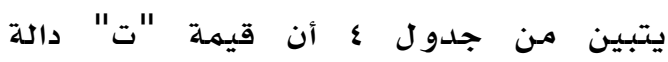
إحصائيا عند مستوى الدلالة (ه...)، ووهذه النتيجة تشير إلى وجود فروق في متوسطات

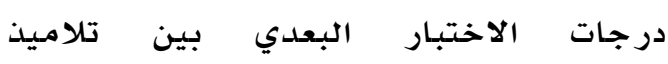

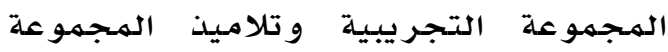

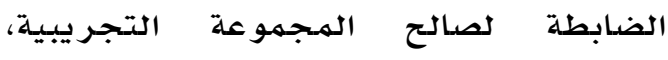

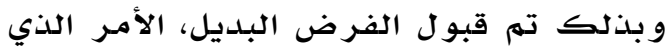

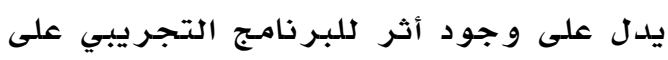

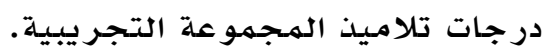
جدول

المتوسط الحساب والانحراف المعياري للرجة التطبيق البعدي

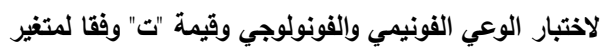

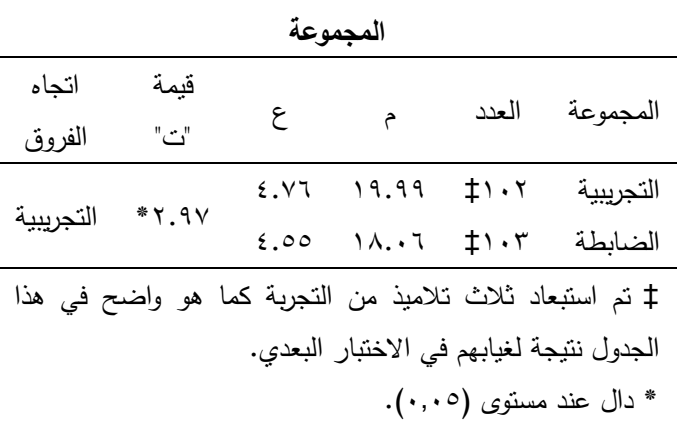


الثلاث (القبلي و البعدي و متابعة الأثر) ). بعد ذلك تم استخدام تحليل التباين للقياسات المتكررة لمعر فة الفروق في درجات اختبار

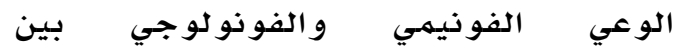

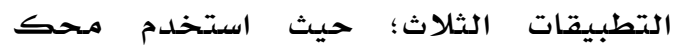
لمعر فة مستوى دلالة المداتم (Greenhouse-Geisser) الفروق، وجدول V يعرض النتائج التي تم التو صل إليها.

ج جدول

المتوسطات الحسابية والانحرافات المعيارية للتطبيقات

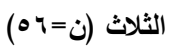

\begin{tabular}{|c|c|c|c|c|}
\hline الأثر & قيمة "ت" & $\varepsilon$ & r & النطبيق \\
\hline \multirow{3}{*}{. .71} & \multirow{3}{*}{$* \wedge \vee . \leqslant 0$} & $\{.01$ & $1 \leq . r V$ & القبلي \\
\hline & & $\varepsilon .1 T$ & $Y . . V V$ & البعدي \\
\hline & & r.0r & r1.. 9 & متابعة الأثُر \\
\hline
\end{tabular}

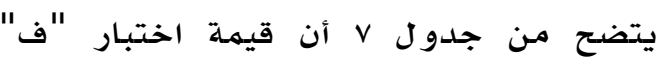
لمحك (Greenhouse-Geisser) دالة احصائيا

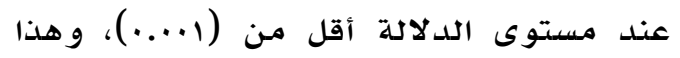
يشير إلى وجود فروق دالة إحصدائيا بين درجات الطلاب في التطبيقات الثلاثة لاختبار

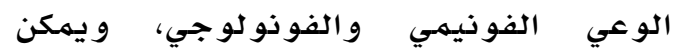

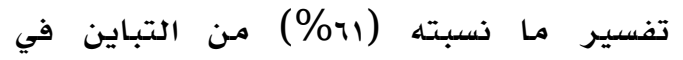
درجات الطلاب بواسطة البرنامـج التجريبي. ولتحديد اتجاه الفروق تم استخدام اختبار

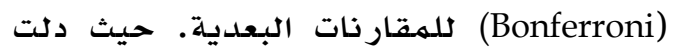

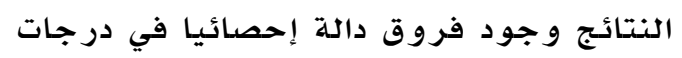
الطلاب بين التطبيقين القبلي و والبعدي البدودي

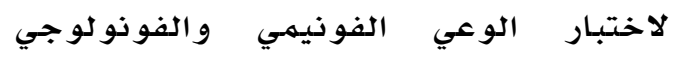

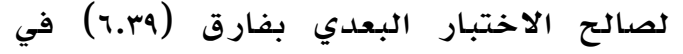

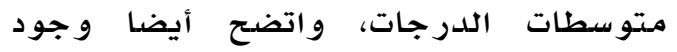
فروق دالة إحصائيا في درجات الطوات الطلاب بين

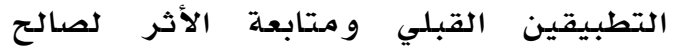

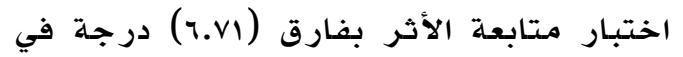
متوسطات درجات الاختبارين. كمها أثارت

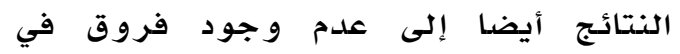
متوسط درجات الطلاب بين التطبين وجودين

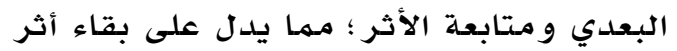
البر نامـج التجري يبي على الطلاب.
النوع الاجتهاعي والمهجموعة (التجر يبية-

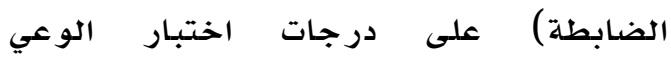
الفونيهي والفونو لوجي في الاختبار البعدي.

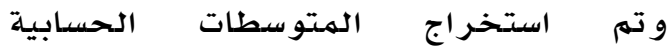

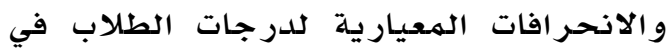

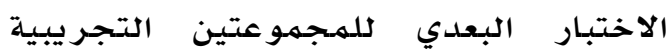
و الضدابطة وفقا لمتغير النوع الاجتماعي، بعد الهد ذلك تم استخدام تحليل التباين الثنائي

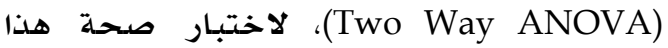
الفر ض، و جدو ل 1 يوضح ذلك. جدول 1 نتائج تحليل التباين الثنائي (Two Way ANOVA) لأثر التفاعل بين متغيري النوع والمجموعة (التجريبية والضابطة)

\begin{tabular}{|c|c|c|c|c|c|c|}
\hline "قت" & التباين & $\varepsilon$ & ? & العدد & المجموعة & النوع \\
\hline \multirow{4}{*}{.$r \wedge$} & \multirow{4}{*}{ النوع المجوعة } & ะ.9V & $19.0 r$ & $\leq 7$ & التجريبية & \multirow{2}{*}{ ذكور } \\
\hline & & $\leq .71$ & 18.91 & or & الضابطة & \\
\hline & & $\{.09$ & r..r & 07 & التجريبية & \multirow{2}{*}{ إناث } \\
\hline & & $\varepsilon . \leqslant 7$ & $|\Lambda| \leqslant$. & 0. & الضابطة & \\
\hline
\end{tabular}

يتضسح من جدول 1 أنه لا يوجد أثر دال إحصائيا عند مستوى الدلالة (.

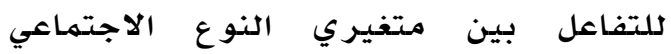
و المججموعة، وهذا يشير إلى تساوي تأثير

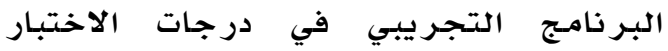

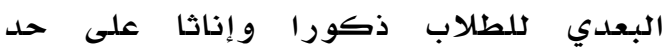
السبو اء.

الفرض الرابع: توجد فروق دالة إحصائيا

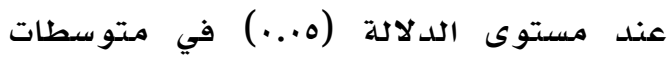
درجات اختبار الوعي الفونيهـي و الفوذولوجي

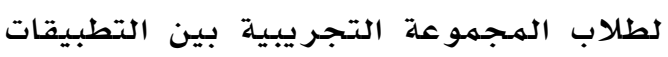
الثلاث؛ القبلي والبعدي و تطبيق متابعة الأثر للاختبار. لاختبار هذا الفرض ضل تم تطبيق الاختبار على عينة قوامها ستار ستة وخمسون

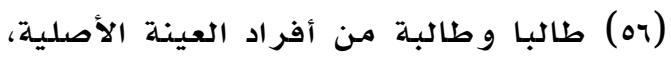

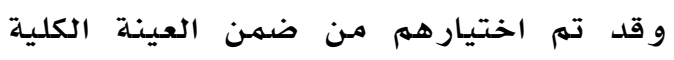

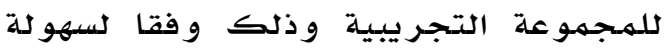
الوصول إليهم. وتم تطبيق الاختبار عليهم

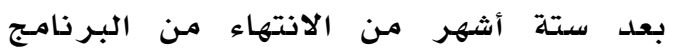

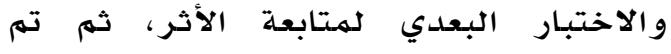

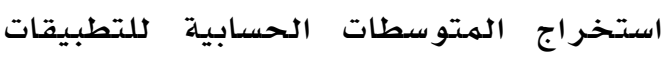


شهرين فقط تم خلالهما تلدريس التتلاميذ مهارات الصوتيات لمدة 10 دقيقة ثلاث أيام أسبوعيا، وذلك خلال الفصل الدراسي الثاني؛ فهذه النتيجة تثبت أن هذا الأسلوب

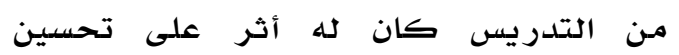
مستويات التتلاميذ فيها يخص التعرف على على صوتيات الحروف الهجائية التي هي أساس تعلم القراءة كما تطالعنا الأبحاث في جميع

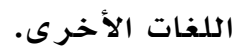

ويرى الباحثون أن تقدم الهـموعة التجرريبية الفيهارنيمية و الفونولوجية في الاختبـار البعدي يرجع بدرجة أسـاسية إلى البـرنامج التجربي يبي ولذا يهيل الباحثون إلى اعتمـاد هذا البـرنامـج في المنهج التدربسي للغهة العربية كوقاية من احتمالية أن تظهر لدى الأطفال أية إصابات

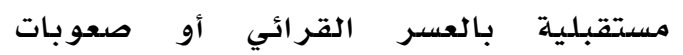
القر اءة (منتصر و آخرون، عاءهاع). كها أظهرت النتائج أيضا تساوي تأثير البـرنامـج التجريبي في درجات الاختبـار البعدي للطلاب ذكورا و إناثا على حد سواء مـما يدل على اكتساب مهارات الوعي

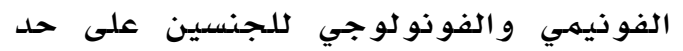
سواء، وهذه النتيجة تعزز من احتمالية تأثير البررنامـج على هذا التقدم؛ حيث إنه له يجد الباحثون آثارا لتأثير خصائص الاناث على أقرانهم الذهور، ولهم يظهر ذلك التأثير أيضسا في الدراسـات السابقة؛ حيث له تظهر إشـارة لمتغير الجنس في معظم الدرر اسات السـابقة.

وفي محاو لة لهعرفة الفروق في درجات الطلاب بين التطبيقات الثلاثة: القبلي و البعدي و تطبيق متتابعة الأثر لاختبـار الوعي الفونيهي والفونولوجي؛ أظهرت النتائج و جود فروق دالة إحصائيا في درجات الطلاب بين التطبيقين القبلي والبعدي الاتبـار الوعي الفونيهـي و الفونولوجي، و اتضح أيضا و جود فروق دالة إحصائيا في درجات الطلاب بين التطبيقين القبلي و والمتابعة، عما

\section{مناقشة النتائج}

هدفت الدراسـة الحالية إلى قياس أثر برنامـج

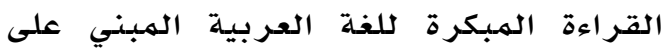

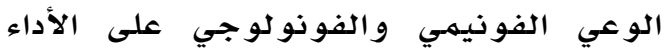

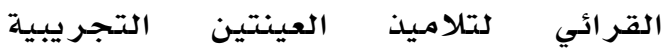

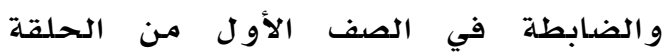

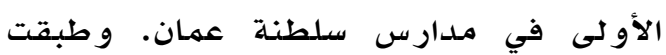

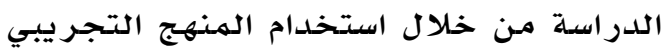

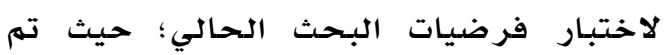

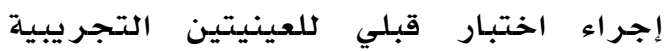

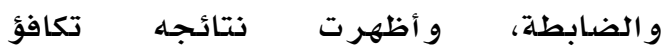

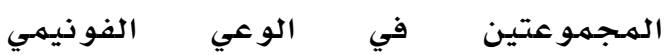

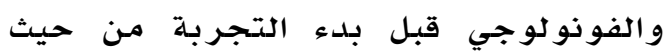

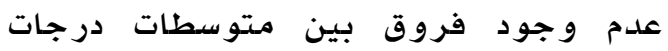

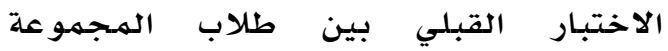
التجر يبية وطلاب المجممو عة الضابطة، إلا أن هذه النتيجة اختلفت في متوسطات التطبيق

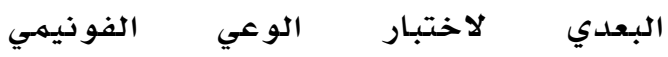

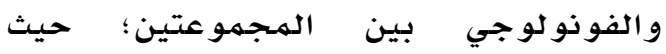
أظهرت وجود فروق في المتوسطات بين

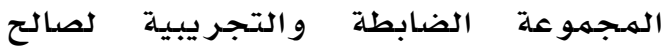

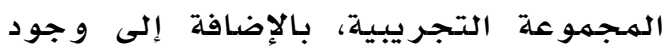

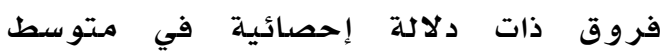

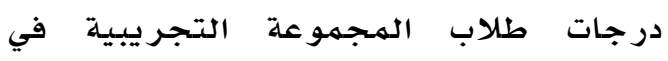
التطبيق القبلي والبعدي لصالح التطبيق

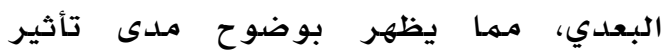

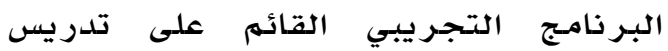

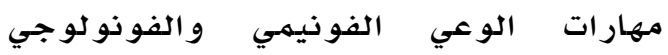
لطلاب المجموعة التجريبية، وذلك الك بمقدار

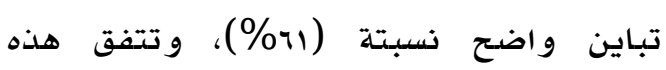

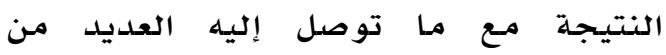

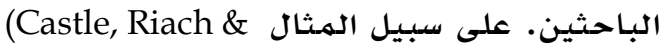
Nicholson, 1994; Ehri et al., 2000; Mann, \& حيث أظهرت نتائج هذه الدر اسـات Foy, 2007) أن تعليهم الوعي الفونيهـي له تأثير إيجابي

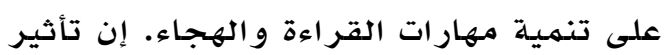

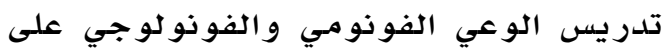

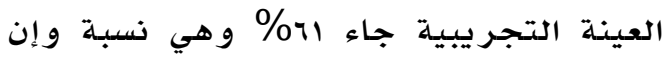
بدت قليلة إلا أذها تعد نسبة الدئة عالية إذاء تم الأخذ بعين الاعتبار أن التطبيق جاء لهدة الهدية 
و يمكننا إذن اعتبار مستوى وعي التلميذ

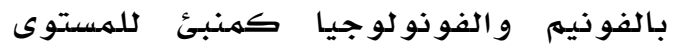

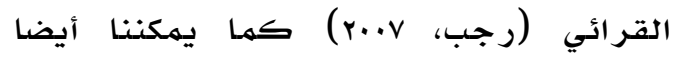
اعتبار ضعف مستواه كسبب رئيس للعسر

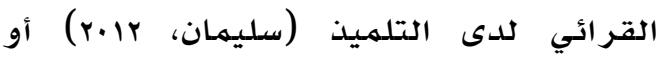
كوسيلة علاجية لمن لديه صعوبة في تعله

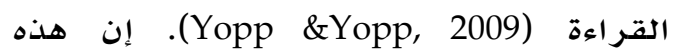

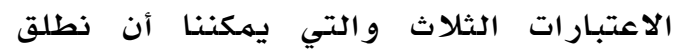

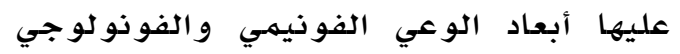

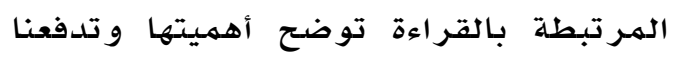
إلى الزعم بأن هناك قصورا في هذا الهـجال عند تدريس اللغة العربم بية (مطر وان والعايد،

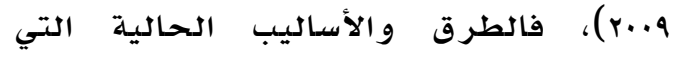
ينتهجها معظم معلهي اللغة العربية عند

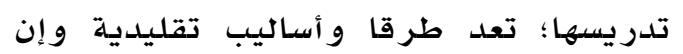
كان هناك بعض الجهود الفردية التي تظهر بين الحين والآخر لدى بعض المعلمين، إلا أننا نتحدث هنا عن منهج أو أسلوبن تدرين بلوريسي

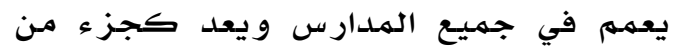

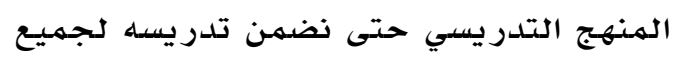
الطلاب؛ فقد أثار أبو الديار وآ آخرون

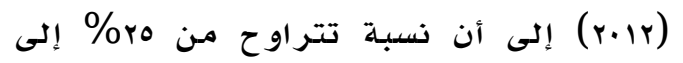

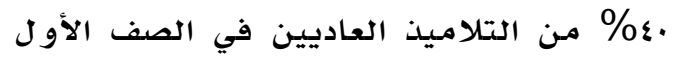

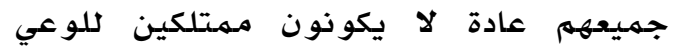

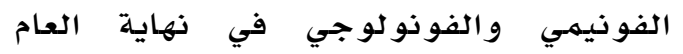
الدراسي، ولذا فهم يحتاجون إلى تدريب

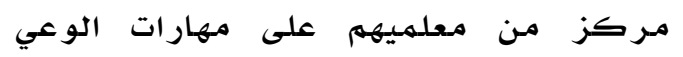

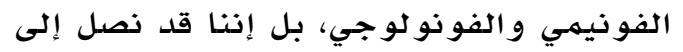

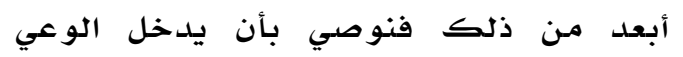

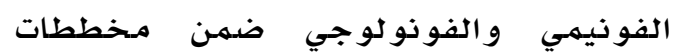
إعداد المعلهم حتى نضمن انتهاجها من ونه الجيل

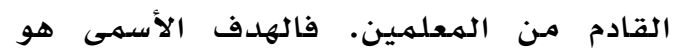
بالفعل إيجاد جيل قارئ واع؛ فالقراءة تعاء تهد من أسـاسيات تقدم المـجتمعات.
يلاحظ عدم وجود فروق في درجات الطلاب بين التطبيقين البعدي والمتابعة مها يدول يلدول

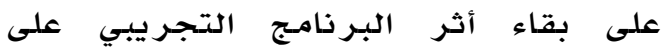
الطلاب؛ ويعني ذلك أنه طالما تواجدت

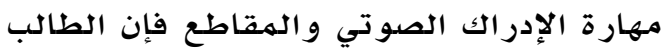

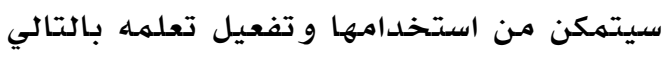
لها، وقد اتفقت هذه النتائجج مـع العديد مـن نتائج الأبحاث والدراسات الطو لية كدر اسات (Deacon, \& Kirby, 2004; Elbro \& Petersen, .2004; Kirby, Parrila, \& Pfeiffer, 2003)

إن نتائج هذه الدراسة و إن كانت تتضمن

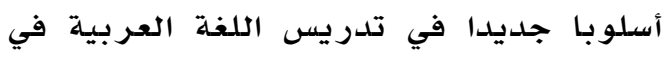

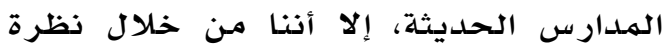

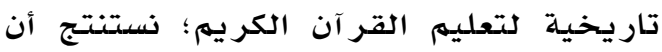

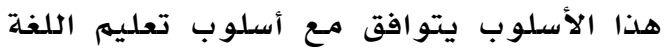

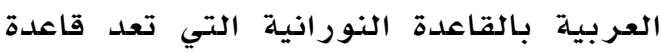

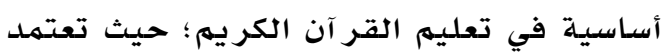

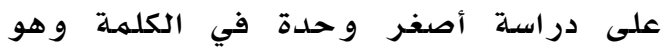
صوت الحرف والهقطع الصوتي و لها أثر

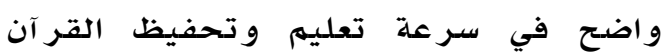
الكريم منـذ أزمنـة الكتاتيب التي توازي

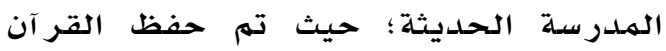

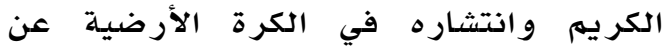
طريق الحفظ الصوتي أكثر منـه عن طريق

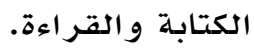

ويمكن تلخيص نتائج الدراسلة الحالية في العبارة التالية: وجود علاقينة بين إدراك الطلاب لأصوات الحروف والكيفية التي يتشكل بها المقطع الصوتي و بين الأداء القرائي. ذلك أن وجود الوعي الصوتي يظهر الأثر الإيجابي لمدى التى تعلهم القراءة،

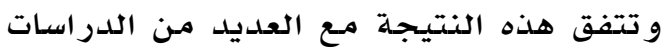

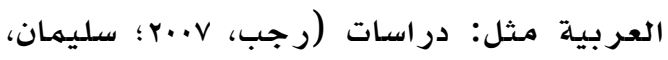

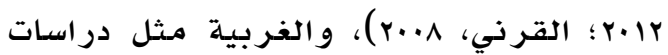
(Anderson, 1985; Hatcher \& Hulme, 1999; Hoien et al., 1995; Lonigan et al., 2000; Macmillan, 2002)

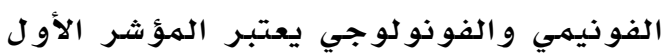
لاكتساب مهار ات القر اءة و الكتابة. 


$$
\text { المراجع }
$$

\section{References}

أبو الديار، مسعد، و محفوظي، عبد الستار، و و إن

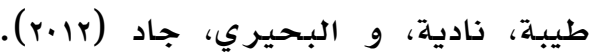
العمليات الفونولوجية وصعوبات القراءة والكتابة. الكويت: مركز تقويم و تعليم

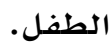

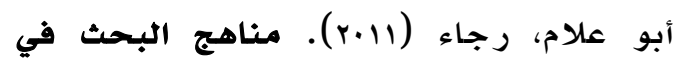
العلوم النفسية والتربوية. القاهرة: دار

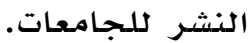

أو لمان، ستيفن. (1999). دور الكلمة في تهمة

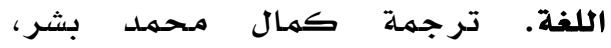
القاهرة: دار غريب للطابعة و والنشر و و التوزيع.

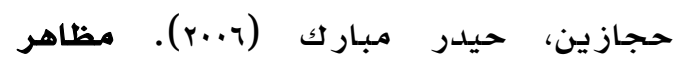
الاضطرابات الفونولوجية النمائية وعلاقتها بصعوبات التعلم في مرحلة

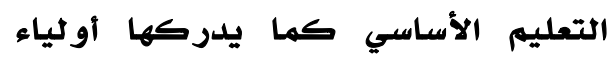
الأمور. رسالة ماجيستير غير منشورة،

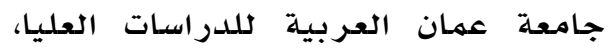

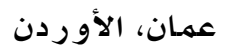

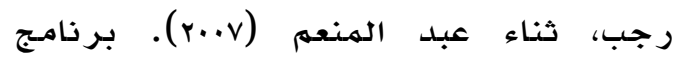
مقترح لعلاج بعض صعوبات القراءة الجهرية وتنمية الوعي الفونو لوجي لوني لدى تلاميذ الصف السادس الابتدائي،

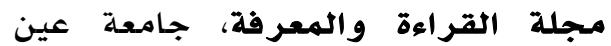

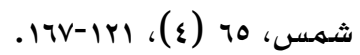

الز املي، علي، وكاظم، علي، و الصارمي، عبد

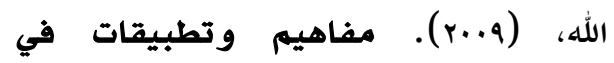

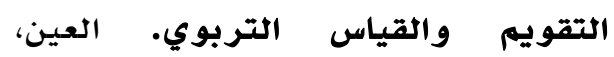
الامارات العربية المتحدة: مكتبة الفلاح لنشر و التوزيع.

سليمان، محمود جلال الدين (rابـ). الوعي الصوتي وعلاج صعوبات القراءة: منظور لغوي تطبيقي. القاهرة: عالم الكتب للنشر و التوزيع.

الشور بجي، سحر ، و الكيو مي، أمل، و الزاملي،

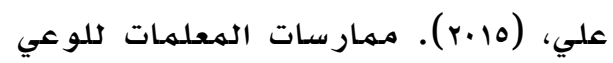

\section{التوصيات}

ا. إدخال برنامج تدريس الوعي الفونيمي

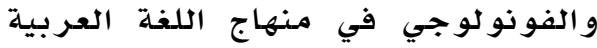
للصف الأول الأساسي والتركئ ولنيز عليه منذ بداية الفصل الدراسي الأول؛ حتى الأى يتمكن الطالب من اكتسابه ومن ثمر الهم الهم

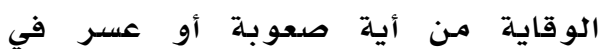
القراءة قد يمكن أن يواجهها لاحقا. r. إدراج بر نام-ج الوعي الفونيمي و الفونو لوجي في مخططات بر امج إعداد معله المجال الأول لتدريبه عليه عليه تمكينهم منه كأساس لتدريس مهارات القر اءة للطلاب.

r. تطبيق برنامج تدريبي متكامل في الوعي

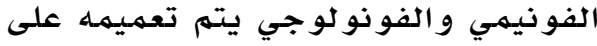

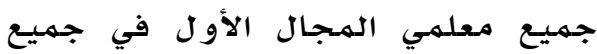

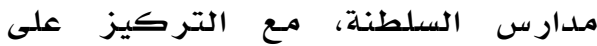

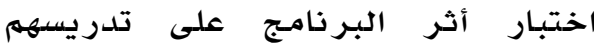
و على نتائج طلابهم في القراءة. ع. تطبيق برنامج تدريبي مماثل في الوعي

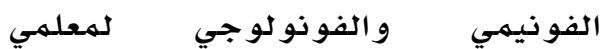

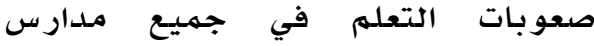
السلطنة واختبار أثره على نتائج طلاب في في

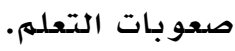

0. إجراء المزيد من البحوث المتعلقة

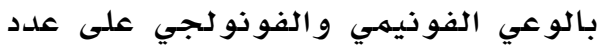
أكبر من الطلاب، وكذلك تعميميم التجربة على معظم محافظات السلطنة، ولفترات أطول من الفترة التي تم فيها تطبيق البحث الحالي من أجل الحصول على نتائج أكثر شمو لية. T. إجراء دراسات تجريبية أخرى مشابهة لتقديم منهاج أعم وأشمل يقوم على دراء تطوير الوعي الفونيمي و الفونولوجي لوني لدى طلبة المرحلة الأساسية. 


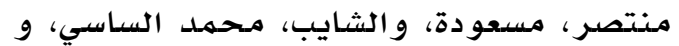

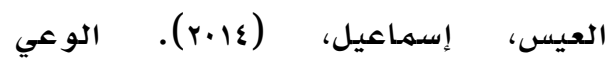

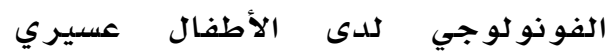

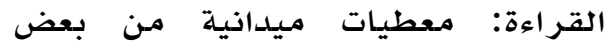

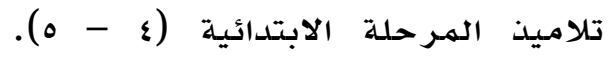

مجلة العلوم الإنسانية والاجتماعية،

جامعة قاصدي مر باح ورقلة، 10(v)، مبا

.ro

الناشف، هدى، (^...r). اعداد الطفل للقراءة

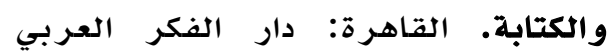

للنشر و التوزيع

هلا لاهان، دنيال؛ كوفمان، جيمس؛ لويل،

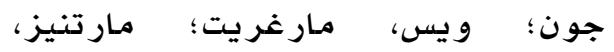

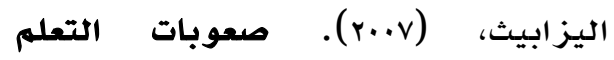

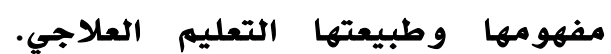

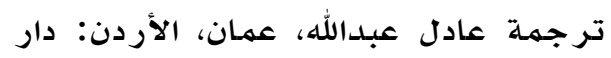

الفكر، ناشرون و موزعون.

وزارة التربية و التعليه العمانية، (10). (r).

الكتاب السنوي الاحصائي. مسقط،

سلطنة عمان: منشورات وزارة التربية

$$
\text { و التعليه. - ولهن. }
$$

Anderson, S. (1985). Phonology in the twentieth century: Theories of rules and theories of representations. Chicago. IL: Univeristy of Chicago Press.

Anthony, J. \& Francis, D. (2005). Development of phonological awareness. Current Directions In Psychological Science, 14(5) 255-259.

Barbosa, T., Miranda, M. C., Santos, R. F. \& Bueno, F. A. (2009) Phonological working memory, phonological awareness and language in literacy difficulties in Brazilian children, Reading and Writing, 22 (2) 201-218.

Bennett, L. ( 1998).Teaching Phonological Awareness With An Emphasis On Linkage To Reading, Simon Fraser University, Phd, Dissertation Abstracts International, 60 (06A), 2111962.
الفونيهي و الفونولوجي في تدريس

القراءة للطلاب العاديين وذوي صعوبات

التعلم في المراحل الأولى مـن التعليم

الأساسي في سلطنة عمان. مـجلة دراسات

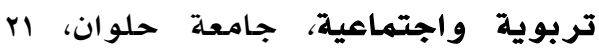
. sr-rva (1)

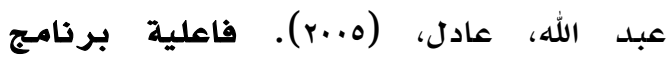
تدريبي لأطفال الروضة في الحد من بعض الآثار السلبية المتربتة على ثصور مهاراتهم قبل الأكاديمية عمؤشر لصعوبات التعلم. المؤتمر العلمي الثالث

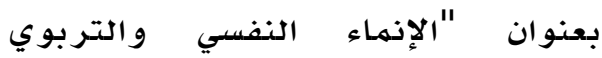
للإِنسان العربي في ضوان إنواء جودة الحياة

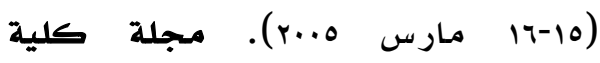

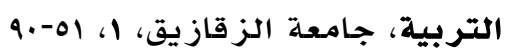

عدس، عبد الرحمن، (1999). أساسيات البحث التربوي. عمان: دار الفرقان لطبـاعة

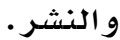

فارع، شحدة، وحمدان، جهاد، جهاد، و عمايرة،

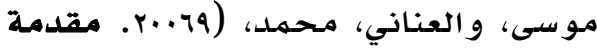

في اللغويات المعاصرة، مولى عمان، الأردن: دار الفرقان للطباعة و النشر.

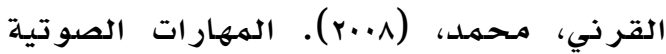

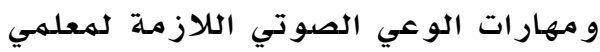

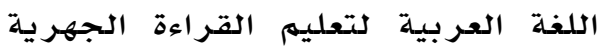
بالصفوف الثلاثة الأولى من الهـرحلة الإبتدائية، مجلة القراءة والمعرفة،

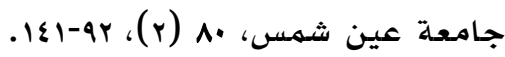
مطر، عبد الفتاح، و العايد، و اصف، (q....). فعالية برنامج باستخدام الحاسوب في

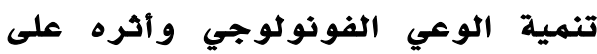

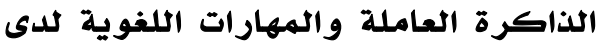
ذوي صعوبات تعلم القراءة، المؤتمر

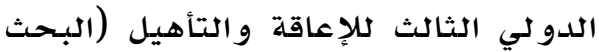
العلمي في مـجال الإعاقة)، مـركز الأمير لهالير

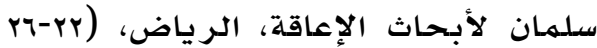

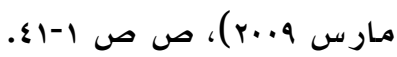


Bernstein, D. \& Tiegerman, E. (1993). Language and communication disorders in children. New York, NY: Macmillan publishing Company.

Castle, J. M.; Riach, J.; Nicholson, T. (1994) Getting off to a better start in reading and spelling: The effects of phonemic awareness instruction within a whole language program, Journal of Educational Psychology, 86(3), 350-359. doi: 10.1037/0022-0663.86.3.350

Davidson, M., \& Jenkins, J. R. (1994). Effects of phonemic processes on word reading and spelling. From:

Deacon, S. H., Eacute, Egrave, NE, \& KIRBY, J. R. (2004). Morphological awareness: Just "more phonological"? The roles of morphological and phonological awareness in reading development. Applied Psycholinguistics, 25 (02), 223-238. doi: doi:10.1017/S0142716404001110

Ehri, L. C., Nunes, S. R., Willows, D. M., Schuster, B. V., Yaghoub-Zadeh, Z., \& Shanahan, T. (2001). Phonemic awareness instruction helps children learn to read: Evidence from the national reading panel's metaanalysis, Reading Research Quarterly, $36,250-287$.

Elbro, C. \& Petersen, D. (2004). Long-term effects of phoneme awareness and letter sound training: An intervention study with children at risk for dyslexia. Journal of Educational Psychology, 96(4), 660-670.

Gall, M., Gall, J. \& Borg. W. (2003). Educational research: An introduction. (7th ed.). Boston, MA: Pearson Education, Inc.

Gallagher ,A., Firth, U., \& Snowling ,M. (2000). Precursors of literacy delay among children at genetic risk of dyslexia. Journal of Child Psychology And Psychiatry, 41, 203-213 .

Gay, L., Mills, G. \& Airasian, P. (2006). Educational research: Competencies for analysis and application, (8th ed). New York: Prentice Hall.

Hatcher, P. J., \& Hulme, C. (1999). Phoneme rhymes, an intelligence as predict of children's responsiveness to remedial reading instruction Evidence From a longitudinal study. Journal of Experimental Child Psychology, 72(2), 130-153.

Hoien, T., Lundberg, I., Stanovich, K. E., \& Bjaaliad, I. (1995). Components of phonological awareness, Reading $\mathcal{E}$ Witting, An Interdisciplinary Journal, 7(2), 171 - 188.

Hsin, Y W.( 2007). Effects of Phonological Awareness Instruction On Pre- reading Skills Of Preschool Children at-Risk for Reading disabilities. Unpublished Doctoral Dissertation, The Ohio State University. Columbus, Ohio, US.

Justice, L. M., Bowles, R. P., and Skibbe, L. E. (2006). Measuring preschool attainment of print-concept knowledge: A study of typical and atrisk 3- to 5-year-old children using item response theory. Language, Speech, and Hearing Services Disorders, 37(3), 224-235

Kirby, John R.; Parrila, Rauno K.; Pfeiffer, Shannon, L. (2003). Naming speed and phonological awareness as predictors of reading development. Journal of Educational Psychology, 95(3), 453-464. doi:10.1037/0022-0663.95.3.453

Lerner, J.W. (2000). Learning disabilities: Theories diagnosis and teaching strategies. (8Th ed), Boston, MA: Houghton Mifflin Company.

Lnigan, C., Burgess, S. \& Anthony, J. (2000). Development of emergent literacy and early reading skills in preschool children: Evidence from a latent variable longitudinal study. Developmental Psychology, 36, 596-613.

Macmillan, B. (2002). Rhyme and reading: a critical review of the research methodology. Journal of Research in Reading, 25(1), 4-42.

Mann, V A., \&Foy, J G. (2007). Speech Development Patterns And Phonological Awareness in Preschool Children. Annals of Dyslexia, 57(1),5174.

Miranda, M., Santos, R.,\& Bueno, O.(2009). Phonological working 
memory, phonological awareness and language in literacy difficulties in Brazilian children. Reading and Writing: An Interdisciplinary Journal, 22(2), 201-218.

National Institute of Child Health and Human Development (2000). Report of the national reading panel. Teaching children to read: An evidence-based assessment of the scientific research literature on reading and its implications for reading instruction: (NIH Publication No. 00-4769).Washington, DC: NICHD Publication

National Early Literacy Panel, (NELP). (2008 a). Developing early literacy: Report of the National Early Literacy Panel. Washington, DC: National Institute of Literacy.

National Early Literacy Panel, (NELP). (2008 a). Developing early literacy: Report of the National Early Literacy Panel. Executive summary. Washington, DC: National Institute of Literacy.

Peeters, M., Verhoeven, L., Moor, J., \& Balkom, H. (2009). Importance of speech production for phonological awareness and word decoding: The case of children with cerebral palsy. Research in Developmental Disabilities, $30(4), 712-726$.

Swanson H. (2000). Are Working memory deficits in readers with learning disabilities hard to change. Journal of Learning Disabilities, 33, 552-566 .

Torgesen, J. K. (2006) A comprehensive K-3 reading assessment plan: Guidance for school leaders. Tallahassee, FL: Florida Center for Reading Research, Florida State Univeristy.

Yopp, H. \& Yopp, K. (2009). Phonological awareness is child's play! Young Children, 64(1), 12-18. 